01,05

\title{
Влияние температуры продолжительного отжига на структуру и магнитные свойства нанокристаллического сплава FeSiNbCuB
}

\author{
() Н.В. Ершов ${ }^{1}$, Ю.П. Черненков ${ }^{2}$, В.А. Лукшина ${ }^{1,3}$, О.П. Смирнов ${ }^{2}$, Д.А. Шишкин ${ }^{1}$ \\ ${ }^{1}$ Институт фризики металлов им. М.Н. Михеева УрО РАН, \\ Екатеринбург, Россия \\ ${ }^{2}$ Петербургский институт ядерной физики им. Б. П. Константинова, НИЦ Курчатовский институт, \\ Гатчина, Россия \\ ${ }^{3}$ Уральский фредеральный университет им. Б.Н. Ельцина, \\ Екатеринбург, Россия \\ E-mail: nershov@imp.uran.ru
}

Поступила в Редакцию 3 марта 2021 г.

В окончательной редакции 8 марта 2021 r.

Принята к публикации 8 марта 2021 г.

Исследуется зависимость мягких магнитных свойств сплава $\mathrm{Fe}_{73.5} \mathrm{Si}_{13.5} \mathrm{Nb}_{3} \mathrm{Cu}_{1} \mathrm{~B}_{9}$ от температуры отжига $T_{a n}$, который проводился на воздухе в течение $2 \mathrm{~h}$ при температурах от 520 до $620^{\circ} \mathrm{C}$. Показано, что с повышением $T_{a n}$ петля магнитного гистерезиса существенно уширяется и становится более наклонной, уменьшается температура Кюри аморфной матрицы, окружающей нанокристаллы $\alpha$-FeSi. Атомная структура и фазовый состав образцов сплава исследованы методом рентгеновской дифракции в геометрии на просвет. После отжига при температурах до $580^{\circ} \mathrm{C}$ нанокристаллы содержат преимущественно фазу $\mathrm{DO}_{3}$ (стехиометрия $\mathrm{Fe}_{3} \mathrm{Si}$ ) и имеют средний размер около $7 \mathrm{~nm}$. Их относительная доля в сплаве увеличивается по мере роста температуры за счет дополнительной диффузии железа из матрицы в нанокристаллы. После отжигов при $T_{a n} \geq 600^{\circ} \mathrm{C}$ средний размер нанокристаллов увеличивается, в дифрактограммах появляются рефлексы кристаллов боридов железа. Ухудшение магнитомягких свойств нанокристаллического сплава $\mathrm{Fe}_{73.5} \mathrm{Si}_{13.5} \mathrm{Nb}_{3} \mathrm{Cu}_{1} \mathrm{~B}_{9}$ при повышении температуры отжига от 520 до $580^{\circ} \mathrm{C}$ объясняется уменьшением концентрации кремния в нанокристаллах $\mathrm{FeSi}$, которое приводит к росту константы магнитокристаллической анизотропии.

Ключевые слова: магнитомягкие материалы, сплав Finemet, зависимость мягких магнитных свойств от температуры отжига.

DOI: $10.21883 /$ FTT.2021.07.51032.041

\section{1. Введение}

Улучшение магнитомягких свойств железокремнистых сталей, имеющих широкое промышленное применение, в основном достигается совершенствованием их кристаллической структуры и текстуры [1]. В 1988 г. в работе [2] впервые было показано, что нанокристаллические сплавы на основе железа и кремния обладают экстраординарными магнитомягкими свойствами [3-5], сочетающими низкие потери на перемагничивание, высокую проницаемость и близкую к нулю магнитострикцию. Особенность новых сплавов заключается в том, что они состоят из зерен $\mathrm{FeSi}$ с объемно-центрированной кубической (ОЦК) решеткой размером порядка $10 \mathrm{~nm}$. По этой причине они получили название „нанокристаллические“, а их мягкие магнитные свойства оказались рекордными. Нанокристаллы такого размера возникают при отжиге аморфного сплава $\mathrm{FeSiB}$, благодаря небольшим добавкам меди, кластеры которой становятся центрами кристаллизации $\mathrm{FeSi}$, и ниобия, препятствующего росту кристаллов [6].

Открытие нанокристаллических сплавов $\mathrm{FeSiNbCuB}$ (Finemet) стимулировало интенсивные исследования, на- правленные на развитие методов их получения, на выяснение механизмов формирования структуры и способов улучшения магнитомягких свойств. Наиболее эффективным методом производства таких сплавов является контролируемая кристаллизация зерен $\alpha$-FeSi при отжиге лент сплава, которые первоначально были получены в квазиаморфном состоянии в результате быстрой закалки из расплава [7]. Если в лабораторных условиях отжиг чаще всего проводится в вакууме или в инертной атмосфере (например, в $\mathrm{He}, \mathrm{Ar}, \mathrm{N}_{2}, \mathrm{H}_{2}$ и т.д.), то при промышленном производстве - на воздухе. Для улучшения магнитомягких свойств делались попытки менять концентрацию элементов в сплаве Finemet [8-16], замещать их другими элементами [17-24], проводить отжиг исходного квазиаморфного сплава за разное время [25] и при различных температурах [8], в магнитном поле или без него [26-31], а также под давлением [32] или растягивающей нагрузкой [33-38].

Для исследования механизмов процесса кристаллизации отжиг аморфных лент проводился в широком интервале температур от 350 до $900^{\circ} \mathrm{C}$ [8,27,37,39-43]. Было показано, что для получения наилучших магнитомягких свойств в сплаве должна пройти первичная кристалли- 
зация, оптимальные температуры которой попадают в интервал $500-600^{\circ} \mathrm{C}$. Выше $600^{\circ} \mathrm{C}$ в матрице начинают кристаллизоваться соединения железа и бора, что приводит к резкому ухудшению магнитных свойств [8]. После отжига образцов сплава $\mathrm{Fe}_{73.5} \mathrm{Si}_{13.5} \mathrm{Nb}_{3} \mathrm{Cu}_{1} \mathrm{~B}_{9}$ в оставшейся аморфной матрице находятся случайно ориентированные нанокристаллы $\alpha$-FeSi c концентрацией кремния $\sim 20 \%$ и размером около $10 \mathrm{~nm}$. В матрице, состоящей из атомов железа, бора и ниобия, остается 20-30\% атомов сплава, и она заполняет промежутки между нанокристаллами в 1-2 nm. Если при высоких температурах отжига Tan за счет диффузии атомов происходит зарождение и рост нанозерен $\alpha$-FeSi, то при низких $T_{a n}$ имеет место релаксация внутренних механических напряжений [44], которые обусловлены технологией приготовления образцов - быстрой закалкой из жидкого состояния.

Косвенным свидетельством возникновения ОЦК-фазы $\mathrm{FeSi}$ является значительное увеличение температуры Кюри $T_{C}$ сплава [45]. Если в аморфном состоянии $T_{C}=250-320^{\circ} \mathrm{C}$, то после нанокристаллизации она достигает $600^{\circ} \mathrm{C}$ при содержании кремния $13.5 \%$ и увеличивается до $740^{\circ} \mathrm{C}$, если содержание кремния опускается до нуля, что соответствует поведению концентрационной зависимости $T_{C}$ магнитомягких железокремнистых сплавов в интервале концентраций железа от 80 до $100 \%$. Остаточная аморфная матрица, содержащая железо, тоже ферромагнитная, но ее температура Кюри, намагниченность насыщения и их концентрационные зависимости отличаются от тех, что наблюдаются у исходного аморфного сплава.

Основные представления о формировании двухфазной структуры и мягких магнитных свойств сплавов системы $\mathrm{FeSiNbCuB}$, подвергнутых нанокристаллизующему отжигу, подробно изложены в обзорах G. Herzer $[3,45]$. Приводятся экспериментальные данные, свидетельствующие о том, что структура и размер $D$ зерна $\alpha$-FeSi определяют петлю гистерезиса ферромагнитного материала. Принципиальное отличие нанокристаллического сплава от обычного железокремнистого сплава с крупным зерном $(D \geq 1 \mathrm{~mm})$ состоит в следующем. Из-за большой плотности энергии магнитокристаллической анизотропии $\left(K_{1} \sim 8 \mathrm{~kJ} / \mathrm{m} 3\right.$, например, в $\alpha$-FeSi при 20 at.\% Si) в каждом отдельном кристаллите намагниченность направлена вдоль его легкой оси $\langle 100\rangle$. Величина $K_{1}$ слишком велика, чтобы объяснить низкую коэрцитивную силу $\left(H_{c}<1 \mathrm{~A} / \mathrm{m}\right)$ и высокую начальную проницаемость $\left(\mu_{i} \approx 10^{5}\right)$, которые наблюдаются в сплавах Finemet. Поскольку матрица ферромагнитная, размер нанокристаллов мал и их оси имеют случайную ориентацию, обменное взаимодействие (с корреляционной длиной $\sim 40 \mathrm{~nm})$ охватывает совокупность нанокристаллов, т. е. препятствует ориентации намагниченности в каждом из них по своей легкой оси. Как следствие, при перемагничивании эффективная анизотропия усредняется по этой совокупности и становится меньше по величине.
Оценка степени усреднения локальной магнитной анизотропии, т.е. уменьшения ее величины в многофазных системах, получена в работах G. Herzer $[8,46]$ в рамках модели случайной анизотропии [47]. При размере зерна $D$ менее корреляционной длины $\sim 40 \mathrm{~nm}$ в эксперименте наблюдаются предсказанные теоретически зависимости $H_{c} \sim D^{6}$ и $\mu_{i} \sim 1 / D^{6}$. Таким образом, получается, что как коэрцитивная сила, так и начальная проницаемость очень сильно зависят от микроструктуры сплава, особенно от величины $D$. В работе [48] теоретически описано наблюдаемое в эксперименте необычное поведение $\mu_{i}$ и $D$ в зависимости от температуры отжига. С ростом $T_{a n}$ размер зерна сначала уменьшается (проницаемость возрастает), а затем увеличивается (проницаемость падает), имеется минимум при $T_{a n} \sim 550^{\circ} \mathrm{C}$.

L.K. Varga и F. Mazaleyrat исследовали и интерпретировали температурную зависимость коэрцитивной силы в пределах от $77 \mathrm{~K}\left(-196^{\circ} \mathrm{C}\right)$ до $850 \mathrm{~K}\left(580^{\circ} \mathrm{C}\right)$ при перемагничивании образцов сплава $\mathrm{Fe}_{73.5} \mathrm{Si}_{13.5} \mathrm{Nb}_{3} \mathrm{Cu}_{1} \mathrm{~B}_{9}$, перед этим подвергнутых отжигу при разных температурах $\left(T_{a n}=500,525,540,575\right.$ и $\left.600^{\circ} \mathrm{C}\right)$ [49]. Как и ожидалось, при температурах, превосходящих точку Кюри аморфной матрицы, магнитная подсистема матрицы выключается и происходит развязка магнитных систем матрицы и кристаллов. И, как следствие, резко, на дватри порядка возрастает коэрцитивная сила. Интересно, что температура развязки практически не зависит от $T_{a n}$ и близка к начальной $T_{C}$ исходного аморфного сплава $(600 \pm 30 \mathrm{~K})$. Было показано, что рост $H_{c}$ уменьшается с увеличением температуры отжига $T_{a n}$, и, как предположили авторы, с увеличением доли кристаллической фазы. Сверхмягкий до развязки материал $\left(H_{c}<1 \mathrm{~A} / \mathrm{m}\right)$ остается магнитомягким после развязки $\left(H_{c} \sim 100 \mathrm{~A} / \mathrm{m}\right)$, если он был кристаллизован при наибольших температурах. Для объяснения эффектов развязки магнитных систем авторы [49] модифицировали модель случайной анизотропии G. Herzer [3] и показали, что модельные результаты, описывающие увеличение коэрцитивной силы по порядку величины, могут быть получены для температур около температуры развязки и выше нее, если учесть дипольное ферромагнитное взаимодействие монодоменных наночастиц, которое оказывается достаточно сильным, чтобы заместить обменное взаимодействие при усреднении локальной магнитной анизотропии в двухфазных нанокристаллических сплавах. Кроме того, при усреднении наряду с магнитокристаллической анизотропией необходимо учитывать анизотропию формы нанокристаллов.

Микроструктура и мягкие магнитные свойства сплава слабо зависят от температуры отжига в диапазоне $500-600^{\circ} \mathrm{C}$. Считается, что нанокристаллы формируются за короткое время (около $10-15 \mathrm{~min}$ ) и не меняются значительно даже после продолжительной термической обработки, проводящейся в течение нескольких h. Типичной является термообработка в течение $1 \mathrm{~h}$ при $540-550^{\circ}$ C. Слишком продолжительный отжиг сильно ухудшает магнитные свойства. Так в работе [25] было 
показано, что коэрцитивная сила мала, $0.14 \mathrm{~A} / \mathrm{m}$, если отжиг длился не более трех часов, и увеличивается до $133 \mathrm{~A} / \mathrm{m}$, если он длился $150 \mathrm{~h}$. Несмотря на то, что размер нанокристаллов и параметр их решетки увеличиваются незначительно, картина доменных полос в образцах в виде лент меняется очень существенно, особенно при отжиге в магнитном поле, что свидетельствует об изменении эффективной магнитной анизотропии за счет вкладов в нее магнитоупругой анизотропии нанокристаллов и аморфной матрицы. В рентгеновской дифрактограмме образца, отожженного в течение $150 \mathrm{~h}$, проявляется один очень слабый пик, который соответствует фазе $\mathrm{Fe}_{3} \mathrm{~B}$, обладающей сильной анизотропией.

Известно [50], что в термодинамическом равновесии бор практически нерастворим в ОЦК-Fе (растворимость $<0.01 \%)$, растворимость меди $(<0.2 \%)$ и ниобия $(<0.1 \%)$ тоже низкая. Если это справедливо и для нанокристаллов, то они должны состоять в основном из $\mathrm{Fe}$ и $\mathrm{Si}$, что и подтверждено в работе [51]. Фактором, способствующим образованию нанокристаллов $\alpha$-FeSi, является разная диффузионная подвижность различных атомов в аморфном сплаве $\mathrm{Fe}_{73.5} \mathrm{Si}_{13.5} \mathrm{Nb}_{3} \mathrm{Cu}_{1} \mathrm{~B}_{9}$, которая рассчитывалась из первых принципов и подробно анализировалась в работе [52]. Как и ожидалось, диффузионная активность $\mathrm{Nb}$ в этом сплаве является самой низкой, а атомов $\mathrm{Cu}$ - самой высокой. Оказалось, что скорость диффузии атомов В также меньше, чем у атомов меди. Диффузии бора препятствует ниобий, поскольку обычно малые атомы обладают гораздо большей диффузионной подвижностью, чем $\mathrm{Fe}, \mathrm{Cu}$ или $\mathrm{Si}$. Наиболее интересной особенностью аморфного сплава на основе железа является предпочтительное локальное соседство атомов $\mathrm{Cu}-\mathrm{Cu}$ и $\mathrm{Nb}-\mathrm{B}$. Поскольку нет данных, указывающих на сильное взаимодействие между атомами меди, локальная концентрация атомов $\mathrm{Cu}$ должна быть вызвана их отталкиванием от богатой железом матрицы и довольно быстрым перераспределением вследствие их большой диффузионной подвижности. Атомы $\mathrm{Nb}$ и В в аморфных сплавах на основе железа связываются друг с другом, что снижает их диффузионную активность, приводит к большому количеству выделений $\alpha$-FeSi на первом этапе кристаллизации и к формированию диффузионного барьера, который предотвращает чрезмерный рост зерен $\alpha$-FeSi.

По данным атомно-зондовой томографии на самой ранней стадии отжига примерно при $T_{a n}=400^{\circ} \mathrm{C}$ в сплаве появляются кластеры меди размером около пяти нанометров и, возможно, сначала аморфные [51,53]. Поскольку образование этих кластеров обусловлено тенденцией к фазовому разделению между медью и железом, то при увеличении температуры отжига или продолжительности выдержки они становятся более четкими. В работе [54] приведены результаты численного моделирования роста и укрупнения кластеров меди, которые комбинировались с экспериментами атомнозондовой томографии. Была определена межфазная энергия кристаллов $\mathrm{Cu}\left(0.54 \mathrm{~J} / \mathrm{m}^{2}\right)$, выделившихся в аморф- ной матрице, и их средний радиус (около $2.5 \mathrm{~nm}$ ), при ширине распределения на половине высоты $1.6 \mathrm{~nm}$.

Структура кластеров $\mathrm{Cu}$ на разных стадиях отжига исследовалась с использованием протяженной тонкой структуры рентгеновских спектров поглощения (Extended X-ray Absorption Fine Structure - метод EXAFS). В работе [55] установлено, что после 30-минутной выдержки образцов сплава при $T_{a n}$, равной 300 и $400^{\circ} \mathrm{C}$, число атомов в первой координационной сфере (КС) $N_{1}$ немного более 8 , а соответствующее межатомное расстояние $a_{1} \approx 0.245 \mathrm{~nm}$, что совпадает с параметрами первой координационной сферы в ОЦК-железе. После отжига при $460^{\circ} \mathrm{C}$ координационное число уменьшается в два раза, а расстояние $a_{1}$ увеличивается до $0.2504 \mathrm{~nm}$, и далее по мере роста $T_{a n}$ как $N_{1}$, так и $a_{1}$ постепенно увеличиваются, достигая после отжига при $T_{a n}=580^{\circ} \mathrm{C}$ величин, характерных для ГЦК-меди $\left(N_{1}=12.0\right.$ и $\left.a_{1} \approx 0.2556 \mathrm{~nm}\right)$, а именно: $N_{1}=12.3$ и $a_{1} \approx 0.2545 \mathrm{~nm}$. Возможно, что малые значения координационного числа $N_{1}$, полученные из EXAFS-спектров образцов, отожженных при 460 и $500^{\circ} \mathrm{C}$, происходят из-за того, что на этой стадии кластеры меди содержат мало атомов, и поэтому: 1) велика доля атомов, расположенных по границе кластера, 2) высока степень дефектности пограничных слоев кластера. Как следствие, многие атомы меди в сплаве имеют не полностью заполненную первую КС.

Результаты EXAFS-исследования локальной структуры вокруг атомов $\mathrm{Cu}$ в сплаве Finemet в исходном (закаленном) состоянии и после отжига при 450,550 и $650^{\circ} \mathrm{C}$, приведенные в [56], оказались весьма неожиданными. Авторы утверждают, что ГЦК-структура $\mathrm{Cu}$ распознается уже в закаленной ленте. Существует небольшое количество медных кластеров, которые имеют очень маленький размер. Это состояние стабильно до $450^{\circ} \mathrm{C}$. При температурах выше $450^{\circ} \mathrm{C}$ кластеры ГЦК-меди быстро развиваются, сохраняясь в сплаве до конца нанокристаллизации. Принято считать, что важная роль кластеров $\mathrm{Cu}$ состоит в том, что они являются центрами зародышеобразования для более крупных наночастиц $\mathrm{Fe}_{3} \mathrm{Si}$ [57], которые отвечают за магнитомягкие свойства отожженных нанокристаллических сплавов Finemet. На границе раздела кластеров $\mathrm{Cu}$ с матрицей $\mathrm{FeSiNbCuB}$ фазы отличаются друг от друга как по химическому составу, так и по структуре: матрица аморфна и богата $\mathrm{Fe}$ и $\mathrm{Si}$, в то время как выделения представляют собой кристаллические кластеры $\mathrm{Cu}$, которые не имеют ни плоскую, ни правильную форму [54].

Несмотря на то, что ранние атомно-зондовые и EXAFS-исследования убедительно показали присутствие кластеров $\mathrm{Cu}$ до начала реакции кристаллизации $\alpha$ - $\mathrm{FeSi}$, было непонятно, как кластеры $\mathrm{Cu}$ стимулируют зародышеобразование основной кристаллической фазы, пока в образце сплава $\mathrm{Fe}_{73.5} \mathrm{Si}_{13.5} \mathrm{Nb}_{3} \mathrm{Cu}_{1} \mathrm{~B}_{9}$, отожженном при $550^{\circ} \mathrm{C}$ в течение $10 \mathrm{~min}$, не было обнаружено выделение меди (Cu-кластер), который находился в прямом контакте с нанокристаллом $\mathrm{FeSi}$ [51]; из этого единичного 
наблюдения был сделан вывод о том, что кластеры $\mathrm{Cu}$ непосредственно служат гетерогенным местом зарождения первичных кристаллов $\mathrm{FeSi}$. В то же время простой анализ дифрактограммы ленты сплава Finemet в исходном состоянии, т.е. сразу после закалки из расплава на вращающееся медное колесо, показывает [58], что уже начальная структура такого сплава может быть определена как мелкозернистая, высоко дефектная ОЦК-структура с размерами зерен около $2 \mathrm{~nm}$, поскольку первый, самый интенсивный, дифракционный пик по угловому положению совпадает с брэгговским рефлексом (110) для ОЦК-железа, а широкие диффузные максимумы расположены близко к расчетным позициям других ОЦК-рефлексов.

Доля кристаллической фазы в отожженных образцах в основном определяется содержанием бора и не зависит от содержания кремния. Как и ниобий, бор препятствует росту зерен - их средний размер уменьшается с увеличением его содержания. Концентрация кремния в зернах значительно больше, чем ее средняя величина в сплаве. В сплаве $\mathrm{Fe}_{73.5} \mathrm{Si}_{13.5} \mathrm{Nb}_{3} \mathrm{Cu}_{1} \mathrm{~B}_{9}$ состав зерен близок к стехиометрическому $\mathrm{Fe}_{3} \mathrm{Si}$, имеющему структуру $\mathrm{D}_{3}$. Рост ОЦК-зерен может продолжаться до тех пор, пока в остаточной аморфной матрице возможно образование стехиометрического $\left(\mathrm{Fe}_{1-z} \mathrm{Nb}_{z}\right)_{2} \mathrm{~B}$. Однако ниобий препятствует образованию кристаллических соединений бора и стабилизирует аморфную структуру матрицы.

Кроме количественного содержания $\mathrm{B}, \mathrm{Nb}$ и $\mathrm{Cu}$, которое определяет размер нанокристаллов, есть и другие факторы, влияющие на формирование рекордных магнитных свойств классического $\mathrm{Fe}_{73.5} \mathrm{Si}_{13.5} \mathrm{Nb}_{3} \mathrm{Cu}_{1} \mathrm{~B}_{9}$, в частности, конкуренция различных типов анизотропии, магнитокристаллической, магнитоупругой, наведенной при отжиге в магнитном поле и магнитострикционной, а также качество образцов-лент (шероховатость поверхности, присутствие примеси и окисных слоев [59] и т.д.). Эти факторы наряду с появлением сильно анизотропной фазы типа $\mathrm{Fe}_{n} \mathrm{~B}$ являются причиной отклонения характеристик петли гистерезиса от простой зависимости $D^{6}$, когда $D$ становится менее $\sim 15 \mathrm{~nm}$. Поскольку нанокристаллы находятся в матрице, которая может оказывать на них воздействие, то необходимо свести к минимуму вклад магнитной анизотропии, например, подбирая способ термообработки. В результате отжига при оптимальных условиях возникают нанокристаллы размером менее ферромагнитной корреляционной длины. Как следствие этого, усредняются, т. е. сильно уменьшаются, не только локальная магнитокристаллическая анизотропия, но и взаимосвязанные с локальной магнитострикцией флуктуации магнитоупругой анизотропии, т.е. формируются необходимые магнитные свойства сплава.

Для того чтобы сформулировать цель и задачи настоящего исследования, следует напомнить утверждение, которое повторяется во многих источниках, например, в обзорах G. Herzer $[3,45]$, о том, что микроструктура и мягкие магнитные свойства сплава $\mathrm{Fe}_{73.5} \mathrm{Si}_{13.5} \mathrm{Nb}_{3} \mathrm{Cu}_{1} \mathrm{~B}_{9}$ слабо зависят от температуры отжига при ее изменении в диапазоне $500-600^{\circ} \mathrm{C}$. Тем не менее в его же статье [8] приводится зависимость коэрцитивной силы $H_{c}$ от температуры отжига $T_{a n}$, ход которой показывает на наличие минимума при $T_{a n} \approx 520^{\circ} \mathrm{C}$. Если между значениями $T_{a n}$ 500 и $520^{\circ} \mathrm{C}$ наблюдается незначительное уменьшение Нc, то после $T_{a n}=540^{\circ} \mathrm{C}$ и тем более после $560^{\circ} \mathrm{C}-$ резкий рост $H_{c}$. Достаточно отметить, что между температурами 560 и $590^{\circ} \mathrm{C}$ коэрцитивная сила увеличивается на два порядка, от 0.01 до $1 \mathrm{~A} / \mathrm{cm}$ (от 1 до $100 \mathrm{~A} / \mathrm{m}$ ). К сожалению, автор в [8] не указал ни время выдержки при отжиге, ни состав атмосферы, окружающей образцы во время отжига, хотя ранее в работе [46] такие же образцы подвергались отжигу в течение $1 \mathrm{~h}$ в атмосфере азота.

Поэтому здесь предпринята и реализована попытка проследить изменение мягких магнитных свойств и атомной структуры сплава $\mathrm{Fe}_{73.5} \mathrm{Si}_{13.5} \mathrm{Nb}_{3} \mathrm{Cu}_{1} \mathrm{~B}_{9}$ в зависимости от температуры отжига на воздухе продолжительностью $2 \mathrm{~h}$ в диапазоне $520-620^{\circ} \mathrm{C}$. Полученные данные позволили установить корреляцию структуры и магнитных свойств, а также объяснить влияние изменений фазового состава сплава на его магнитные свойства.

\section{2. Образцы и методика эксперимента}

Сплавы $\mathrm{Fe}_{73.5} \mathrm{Si}_{13.5} \mathrm{Nb}_{3} \mathrm{Cu}_{1} \mathrm{~B}_{9} \quad$ и $\quad \mathrm{Fe}_{76} \mathrm{Si}_{11} \mathrm{Nb}_{3} \mathrm{Cu}_{1} \mathrm{~B}_{9}$ в исходном (квазиаморфном) состоянии получены в виде лент толщиной около $20 \mu \mathrm{m}$ и шириной около $1 \mathrm{~mm}$ быстрой закалкой на воздухе расплава, падающего на вращающийся медный барабан [35,58]. Затем отрезки ленты сплава $\mathrm{Fe}_{73.5} \mathrm{Si}_{13.5} \mathrm{Nb}_{3} \mathrm{Cu}_{1} \mathrm{~B}_{9}$ длиной около $100 \mathrm{~mm}$ подвергались отжигу в течение $2 \mathrm{~h}$ при температурах $T_{a n}=520,540,560,580,600$ и $620^{\circ} \mathrm{C}$ для нанокристаллизации, т. е. для кристаллизации с формированием нанозерен. Отжиги проводились на воздухе. Были получены образцы сплава $\mathrm{Fe}_{73.5} \mathrm{Si}_{13.5} \mathrm{Nb}_{3} \mathrm{Cu}_{1} \mathrm{~B}_{9}$ с изменяющимися по мере повышения температуры $T_{a n}$ структурой и магнитными свойствами.

Магнитное состояние образцов контролировалось по петлям гистерезиса, измеренным в открытой магнитной цепи с помощью гальванометрического компенсационного микровеберметра. Из петель гистерезиса, полученных в полях до \pm 8000 A/m, приложенных вдоль оси ленты, определялись коэрцитивная сила $H_{c}$, максимальная индукция $B_{m}$ и остаточная индукция $B_{r}$. Погрешность измерения составляла $3 \%$ для $H_{c}$ и $7 \%$ для $B_{r}$ и $B_{m}$. Температурная зависимость удельной намагниченности насыщения сплава $\sigma(T)$ при нагреве от 20 до $740^{\circ} \mathrm{C}$ измерялась в образцах сплава длиной $5 \mathrm{~mm}$, отожженных при температурах $T_{a n}$, равных 520 и $540^{\circ} \mathrm{C}$. Измерения выполнялись с использованием вибромагнитометра Lake Shore 7407 VSM в поле $5 \mathrm{kOe}(400 \mathrm{kA} / \mathrm{m})$, относительная погрешность измерений не превышала $1 \%$.

После магнитных измерений из лент были нарезаны фрагменты длиной 5-6 mm, которые наклеивались на оправки в форме колец параллельно друг другу в два 
перекрывающихся слоя толщиной $\sim 40 \mu \mathrm{m}$. На них были проведены структурные исследования методом рентгеновской дифракции.

Дифрактограммы сплавов измерялись на четырехкружном рентгеновском дифрактометре (ПИЯФ, НИЦ Курчатовский институт) в геометрии на просвет с использованием монохроматизированного рентгеновского излучения $(\lambda=0.71 \AA)$. Для каждого образца с помощью $\theta-2 \theta$ сканирования были получены две дифрактограммы: одна, когда вектор рассеяния направлен вдоль оси ленты, а вторая, когда он перпендикулярен оси ленты, но лежит в плоскости образца. Поскольку интенсивности рассеяния в дифрактограммах в пределах статистической точности не различаются, то результаты измерений суммировались.

\section{3. Результаты и обсуждение}

Петли магнитного гистерезиса, измеренные при перемагничивании образцов сплава $\mathrm{Fe}_{73.5} \mathrm{Si}_{13.5} \mathrm{Nb}_{3} \mathrm{Cu}_{1} \mathrm{~B}_{9}$ после кристаллизации в течение $2 \mathrm{~h}$ при температурах $T_{a n}$ от 520 до $620^{\circ} \mathrm{C}$ с шагом в $20^{\circ}$, приведены на рис. 1. При повышении температуры кристаллизации петли становятся более наклонными, что говорит о постепенном затруднении процессов намагничивания и перемагничивания.

Значения коэрцитивной силы, определенные из этих петель, приведены в табл. 1, а ее температурная зависимость в интервале температур отжига $520-600^{\circ} \mathrm{C}$ показана на рис. 2. Увеличение коэрцитивной силы при увеличении температуры отжига наблюдалось ранее, например, в работах $[8,44,60]$.

Ранее было показано [35], что увеличение содержания железа за счет кремния в отожженных образцах сплава приводят к аналогичному эффекту. Например,

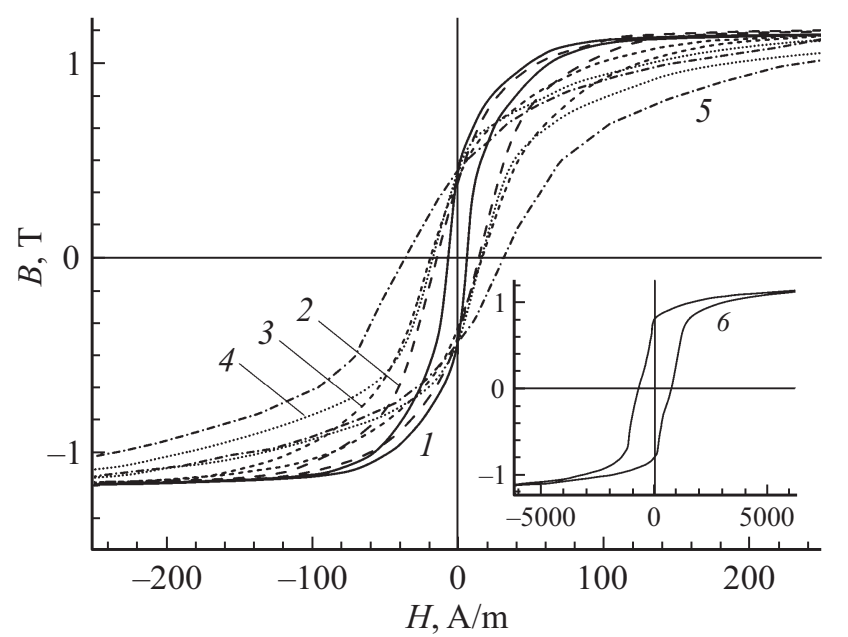

Рис. 1. Петли гистерезиса образцов сплава $\mathrm{Fe}_{73.5} \mathrm{Si}_{13.5} \mathrm{Nb}_{3} \mathrm{Cu}_{1} \mathrm{~B}_{9}$ после кристаллизации в течение $2 \mathrm{~h}$ при температурах: $1-520,2-540,3-560,4-580$, $5-600$ и $6-620^{\circ} \mathrm{C}$ (на вставке внизу справа).

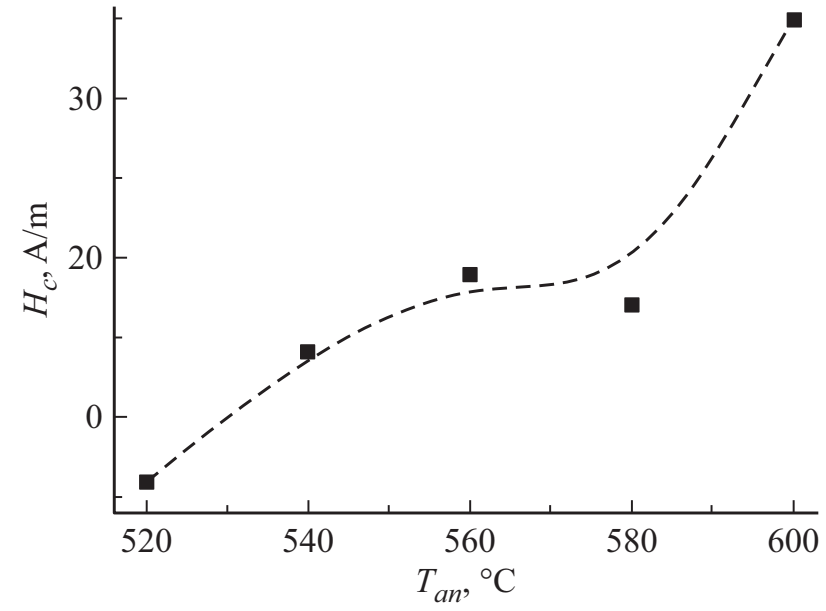

Рис. 2. Зависимость коэрцитивной силы от температуры отжига $T_{a n}$ в интервале температур от 520 до $600^{\circ} \mathrm{C}$.

при переходе от образца сплава $\mathrm{Fe}_{73.5} \mathrm{Si}_{13.5} \mathrm{Nb}_{3} \mathrm{Cu}_{1} \mathrm{~B}_{9}$ к образцу сплава $\mathrm{Fe}_{76} \mathrm{Si}_{11} \mathrm{Nb}_{3} \mathrm{Cu}_{1} \mathrm{~B}_{9}$ (образцы получены одинаковым способом, в результате кристаллизации в течение $2 \mathrm{~h}$ при температуре $520^{\circ} \mathrm{C}$ ) петля магнитного гистерезиса становится более наклонной, увеличиваются индукция насыщения от 1.25 до 1.28 или на 2.5\% и коэрцитивная сила в 8 раз от 0.48 до $3.90 \mathrm{~A} / \mathrm{m}$. Естественно связать эти изменения магнитных свойств с увеличением средней концентрации железа в сплаве. При этом, скорее всего, в нанокристаллах также увеличивается объемная доля железа, что обосновывается соотношениями химических составов в нанокристаллах и аморфной матрице, приведенных в обзоре [3]. Поскольку вклад нанокристаллов в намагниченность образцов сплава является доминирующим, то можно предположить, что ухудшение магнитомягких свойств как при повышении температуры отжига, так и при увеличении концентрации железа обусловлено увеличением доли железа в нанокристаллах.

На рис. 3 приведена температурная зависимость намагниченности насыщения в образцах сплава $\mathrm{Fe}_{73.5} \mathrm{Si}_{13.5} \mathrm{Nb}_{3} \mathrm{Cu}_{1} \mathrm{~B}_{9}$, предварительно подвергнутых нанокристаллизующему отжигу при температурах

Таблица 1. Коэрцитивная сила, Нс, определенная из петли гистерезиса, измеренной в поле $\pm 8 \mathrm{kA} / \mathrm{m}$ после кристаллизации образцов сплава $\mathrm{Fe}_{73.5} \mathrm{Si}_{13.5} \mathrm{Nb}_{3} \mathrm{Cu}_{1} \mathrm{~B}_{9}$ при температуре $T_{a n}$, изменяющейся от 520 до $620^{\circ} \mathrm{C}$

\begin{tabular}{c|c}
\hline$T_{a n},{ }^{\circ} \mathrm{C}$ & $H_{c}, \mathrm{~A} / \mathrm{m}$ \\
\hline 520 & 6 \\
540 & 14 \\
560 & 19 \\
580 & 17 \\
600 & 35 \\
620 & 740
\end{tabular}




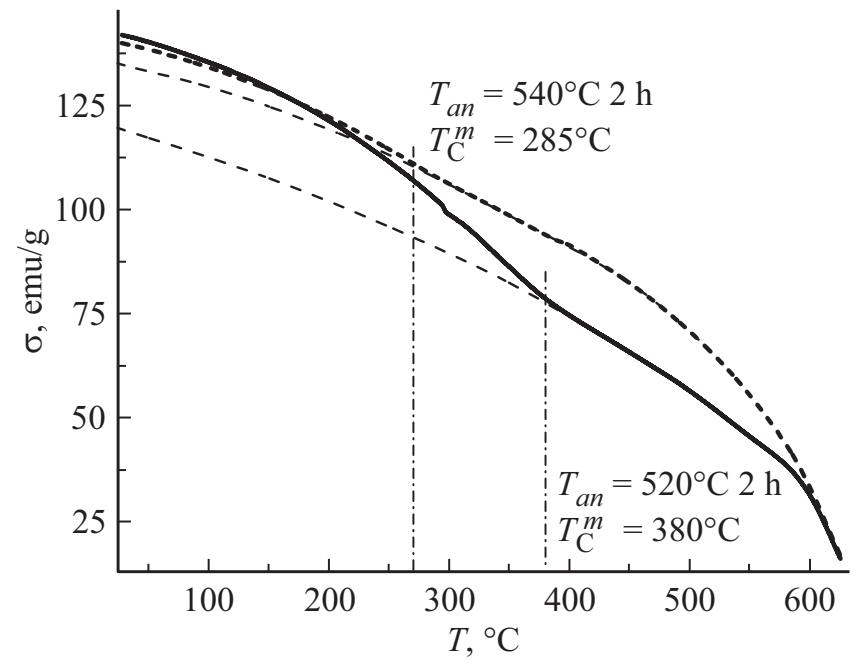

Pис. 3. Температурная зависимость намагниченности в магнитном поле $5 \mathrm{kOe}$ образцов сплава $\mathrm{Fe}_{73.5} \mathrm{Si}_{13.5} \mathrm{Nb}_{3} \mathrm{Cu}_{1} \mathrm{~B}_{9}$, подвергнутых нанокристаллизующему отжигу при температурах 520 и $540^{\circ} \mathrm{C}$. Экстраполяция намагниченности из области $400-500^{\circ} \mathrm{C}$ в сторону меньших температур (штриховые линии) позволяет оценить температуру Кюри $\left(T_{C}^{m}\right)$ аморфной матрицы в каждом из образцов сплавов после нанокристаллизации (вертикальные штрихпунктирные прямые).

$T_{a n}=520$ и $540^{\circ} \mathrm{C}$. Кривые $\sigma(T)$ измерены в магнитном поле $5 \mathrm{kOe}$, которое гарантированно обеспечивает намагничивание до насыщения. Перепады скорости снижения намагниченности объясняются тем, что после нанокристаллизации при комнатных температурах она складывается из вкладов двух ферромагнитных систем: нанокристаллов и остаточной аморфной матрицы, каждая из которых имеет свою точку перехода в парамагнитное состояние - температуру Кюри [3].

Если температура Кюри нанокристаллов $\alpha$-FeSi $\left(T_{C}^{n}=630^{\circ} \mathrm{C}\right.$ по нашим данным $)$ и массивных кристаллов кремнистого железа имеют близкие значения (в чистом железе $T_{C}^{\mathrm{Fe}}=720^{\circ} \mathrm{C}$, по мере увеличения содержания кремния уменьшается и при 20 at.\% $\mathrm{Si}$ равна $610^{\circ} \mathrm{C}$ ), то аморфная матрица переходит в парамагнитное состояние при гораздо меньших температурах (например, в обзоpe [3] приводится значение $\left.T_{C}^{m}=290^{\circ} \mathrm{C}\right)$. Если экстраполировать намагниченность из интервала температур $400-500^{\circ} \mathrm{C}$, в котором вклад в $\sigma(T)$ дают только нанокристаллы $\alpha$-FeSi, в сторону меньших температур (результаты в виде функций $\sigma_{n}=\sigma_{0 n}\left(1-T / T_{C}^{n c}\right)^{\beta}$, показаны штриховыми линиями на рис. 3 ), то температура, при которой подключается матрица, соответствует точке $T_{C}^{m}$, в которой результат экстраполяции начинает расходиться с экспериментальной намагниченностью $\sigma(T)$, а разность $\sigma(T)-\sigma_{n}(T)$ является вкладом аморфной матрицы $\sigma_{m}=\sigma_{0 m}\left(1-T / T_{C}^{m}\right)^{\beta}$ в общую намагниченность [9]. Здесь $T_{C}^{m}=380^{\circ} \mathrm{C}$ после отжига при температуре $520^{\circ} \mathrm{C}$ и $T_{C}^{m}=285^{\circ} \mathrm{C}$ после отжига при температуре $540^{\circ} \mathrm{C}$.
Температурные зависимости намагниченности насыщения, приведенные на рис. 3, позволяют проследить тенденции тех изменений, которые происходят в сплаве при увеличении температуры нанокристаллизующего отжига $T_{a n}$ от 520 до $540^{\circ} \mathrm{C}$. Поскольку понижается температура Кюри аморфной матрицы с химическим составом $(\mathrm{Fe}, \mathrm{Nb}) \mathrm{B}$, то можно предположить, что в ней уменьшается содержание железа, скорее всего, из-за его дополнительной диффузии из матрицы в нанокристаллы при более высокой $T_{a n}$. Ранее было показано [35,58], что в образцах сплава $\mathrm{Fe}_{87-X} \mathrm{Si}_{X} \mathrm{Nb}_{3} \mathrm{Cu}_{1} \mathrm{~B}_{9}$, отожженных в течение $2 \mathrm{~h}$ при температуре $520^{\circ} \mathrm{C}$, при уменьшении средней концентрации кремния $X$ от 13.5 до 0 уменьшается его относительное содержание в нанокристаллах $\alpha$-FeSi. Доля железа растет, что сопровождается увеличением параметра ОЦК-решетки нанокристаллов и уменьшением объемной доли фазы $D_{3}$ вплоть до ее полного исчезновения. В то же время, несмотря на рост индукции насыщения, мягкие магнитные свойства ухудшаются повышается коэрцитивная сила, увеличивается наклон петли магнитного гистерезиса.

В дифрактограммах образцов сплава $\mathrm{Fe}_{73.5} \mathrm{Si}_{13.5} \mathrm{Nb}_{3} \mathrm{Cu}_{1} \mathrm{~B}_{9}$ после отжига при температурах $T_{a n}$ от 520 до $620^{\circ} \mathrm{C}$, которые приведены на рис. 4, наблюдаются пики с миллеровскими индексами (110), $(200),(211)$ и далее до (431) и (510) для ОЦК-решетки $\alpha$-FeSi. Поскольку параметр элементарной ячейки фазы $\mathrm{Fe}_{3} \mathrm{Si}$ (сверхструктура типа $\mathrm{DO}_{3}$ ) примерно вдвое больше, чем для ОЦК-структуры, то при имеющемся разрешении дифрактометра ОЦК-пики с индексами $(h, k, l)$ в дифрактограммах совпадают с $D 0_{3}$-пиками $\left(h_{D}, k_{D}, l_{D}\right)$, где $h_{D}=2 h, k_{D}=2 k$ и $l_{D}=2 l$ - целые четные числа. На углах рассеяния, меньших, чем угол $2 \theta_{110}$ пика (110) для ОЦК-решетки, отчетливо видны два сверхструктурных пика с индексами $(111)_{D}$ и $(200)_{D}$ для $D 0_{3}$-решетки. Пики $(220)_{D},(400)_{D},(422)_{D}$ и др., которые совпадают с разрешенными пиками (110), (200), (211) и др. ОЦК-решетки нанокристаллов, на рис. 4 не показаны. На углах рассеяния $2 \theta$ около 24 и $25^{\circ}$ наблюдаются пики $(311)_{D}$ и $(222)_{D}$, более удаленные $D 0_{3}$-пики слабы и на общем фоне интенсивности рассеяния не проявляются.

Кроме того, в дифрактограммах можно выделить осциллирующий вклад рассеяния от аморфной матрицы части сплава, остающейся после нанокристаллизации в аморфном состоянии. Два широких максимума этого вклада наблюдаются под очень сильным брэгговским пиком (110) около $2 \theta \approx 20^{\circ}$ и под пиками $(200)$ и $(211)$ около $2 \theta \approx 34^{\circ}$. Матрица содержит металлы $\mathrm{Fe}, \mathrm{Nb}$ и В в качестве аморфизующего элемента и небольшие (до $5 \mathrm{~nm}$ ) ГЦК-кластеры меди [3,51]. Последние не дают заметного вклада в рентгеновское рассеяние из-за их малых размеров и относительно малого количества.

После отжига образца сплава при температуре $620^{\circ} \mathrm{C}$ в его дифрактограмме появляются очень слабые пики боридов железа $\left(2 \theta \approx 17.4,22.6\right.$ и $\left.32.9^{\circ}\right)$, что сопровождается резким ухудшением магнитных свойств - 


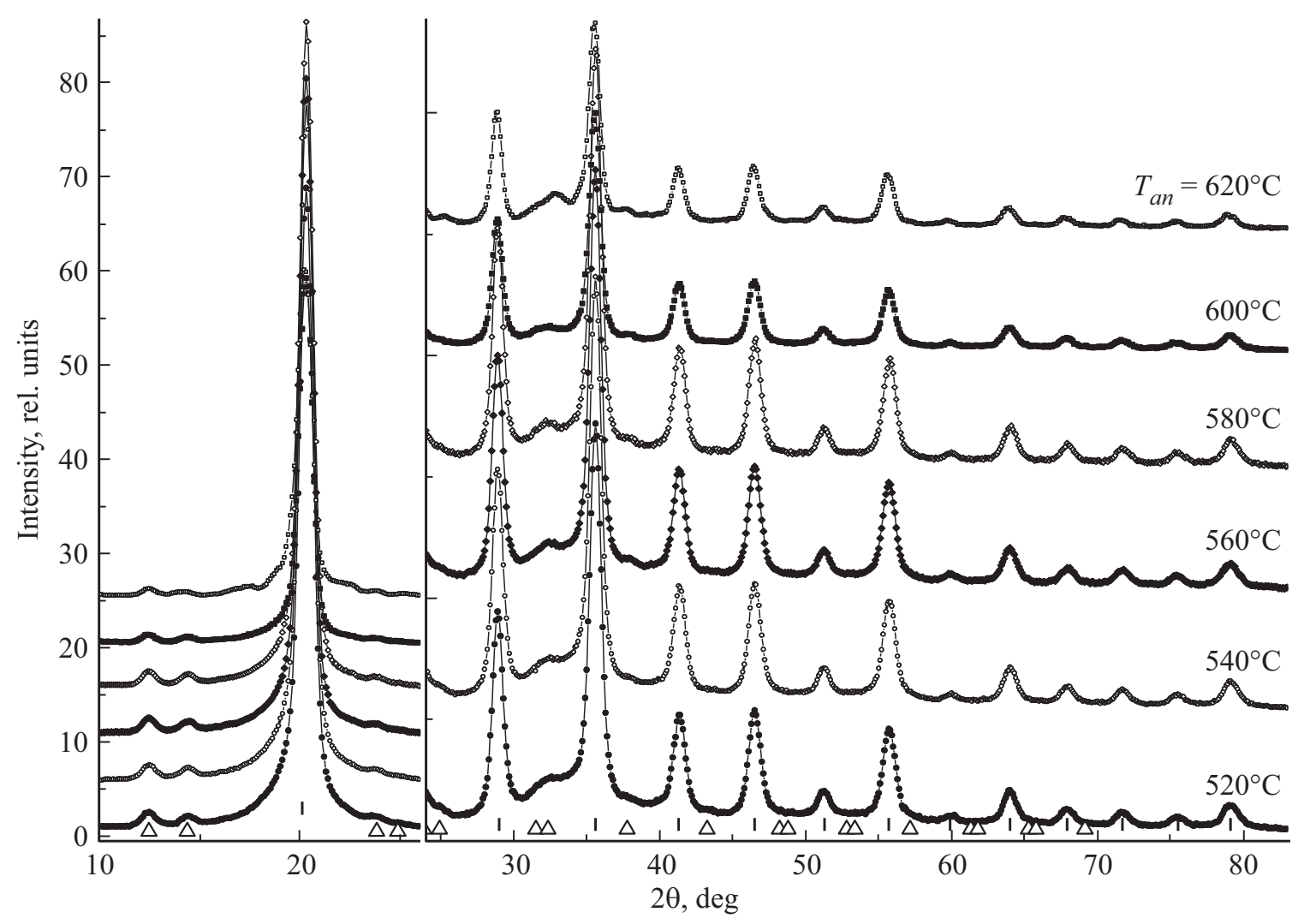

Рис. 4. Дифрактограммы образцов сплава $\mathrm{Fe}_{73.5} \mathrm{Si}_{13.5} \mathrm{Nb}_{3} \mathrm{Cu}_{1} \mathrm{~B}_{9}$, подвергнутых нанокристаллизующему отжигу при температурах от 520 до $620^{\circ} \mathrm{C}$ в течение $2 \mathrm{~h}$. Интенсивности в правой части увеличены примерно в 2.5 раза. Отмечены позиции брэгговских рефлексов ОЦК-решетки (штрихи) и не совпадающих с ними сверхструктурных рефлексов фазы $D 0_{3}$ (светлые треугольники). Ошибка измерений имеет величину порядка размера символа (точки).

петля магнитного гистерезиса на вставке рис. 1 - и свидетельствует о начале в сплаве процесса вторичной кристаллизации [3]. Поскольку результаты вторичной кристаллизации выходят за рамки настоящего исследования, то из дальнейшего анализа атомной структуры сплавов дифрактограмма образца, подвергнутого продолжительному отжигу при наибольшей температуре, равной $620^{\circ} \mathrm{C}$, будет исключена.

На рис. 5 показан результат разложения с использованием метода наименьших квадратов (МНК) одной из дифрактограмм. На рис. 5 показан результат разложения с использованием метода наименьших квадратов (МНК) одной из дифрактограмм, в которой были выделены: (1) монотонно спадающий фон, (2) брэгговские пики от ОЦК-решетки нанокристаллов, (3) сверхструктурные пики от фазы $\mathrm{DO}_{3}$ (только те, которые не совпадают с ОЦК-пиками) и (4) вклад в рассеяние от оставшейся в аморфном состоянии матрицы. Форма брэгговских пиков описывалась функцией Войта, т.е. суммой гауссиана и лоренциана, имеющих одинаковую ширину на полувысоте. Описать корректно вклад в рассеяние от аморфной матрицы очень сложно, особенно ту его часть на больших углах, что расположена за двумя очевидными максимумами. Поскольку цель разложения состояла всего лишь в выяснении тенденции изменения с температурой отжига вкладов от фаз ОЦК и $\mathrm{DO}_{3}$, a также от аморфной матрицы, ее вклад при углах рассеяния $2 \theta>40^{\circ}$ был описан совокупностью четырех гауссианов для $T_{a n}=520^{\circ} \mathrm{C}$, а для других температур отжига положение и ширина этих гауссианов не варьировалась. Относительная разность $(\Delta /$ Int $)$ между расчетной и экспериментальной (Int) интенсивностями в каждой точке показана внизу на рис. 5.

Полученные в результате МНК-разложения суммарные интегральные интенсивности вкладов нанокристаллов $\left(I_{N C}\right.$ - сумма интенсивностей пиков, соответствующих фазам ОЦК и $\left.D 0_{3}\right)$, областей $D 0_{3} \quad\left(I_{D 03}-\right.$ сумма пиков $(111)_{D},(200)_{D},(311)_{D}$ и $\left.(222)_{D}\right)$, а также аморфной матрицы $\left(I_{A M}\right.$ - сумма четырех гауссианов $)$ позволяют оценить относительные доли фаз и проследить их изменение с температурой отжига.

В табл. 2 приведены доли (в \%) суммарных интенсивностей $I_{N C}, I_{D 03}$ и $I_{A M}$ и их отношения для отжига при температуре $T_{a n}$ от 520 до $600^{\circ} \mathrm{C}$ продолжительностью $2 \mathrm{~h}$. По мере увеличения температуры отжига от 520 до $580^{\circ} \mathrm{C}$, т.е. в интервале температур, который считается оптимальным для формирования в сплаве $\mathrm{Fe}_{73.5} \mathrm{Si}_{13.5} \mathrm{Nb}_{3} \mathrm{Cu}_{1} \mathrm{~B}_{9}$ магнитомягких свойств, доля вклада нанокристаллов $\alpha$-FeSi увеличивается, а матрицы уменьшается. В то же время в пределах погрешности 


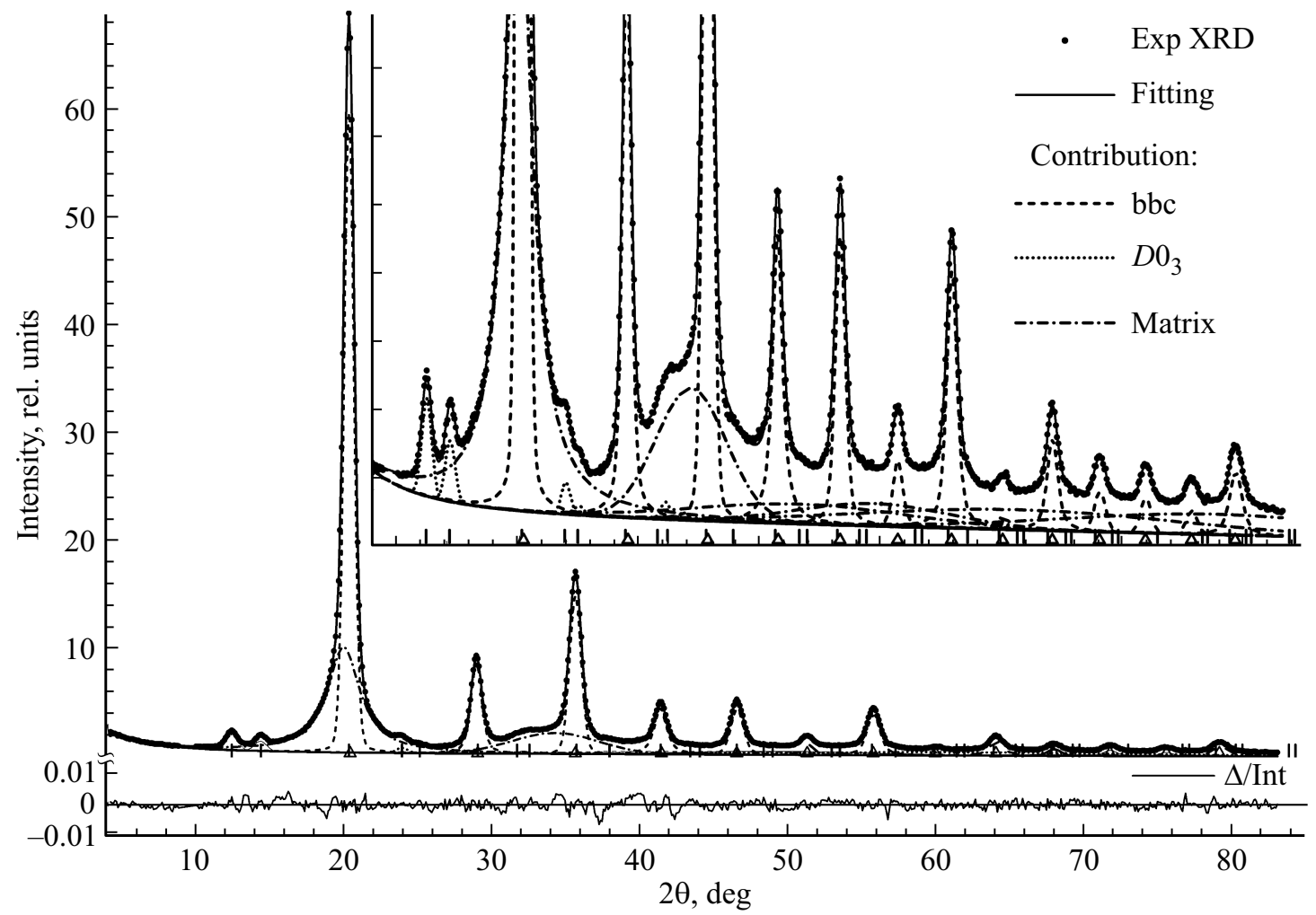

Рис. 5. Разложение дифрактограммы образца, подвергнутого нанокристаллизующему отжигу при температуре $520^{\circ} \mathrm{C}$ в течение $2 \mathrm{~h}$, методом наименьших квадратов. Вклад в узкие пики дают ОЦК (bcc) нанокристаллы $\alpha$ - $\mathrm{FeSi}$ и области с $D 0_{3}$-упорядочением. Широкие пики описывают рассеяние от аморфной матрицы (matrix). Внизу приведена величина относительной разницы $(\Delta / \mathrm{Int})$ между расчетной и экспериментальной (Int) интенсивностями в каждой точке. На вставке для большей наглядности те же данные приведены в меньшем диапазоне интенсивности рассеяния.

вклад от областей $\mathrm{DO}_{3}$ остается неизменным. Отношения вкладов изменяются в соответствии с изменением их доли в дифрактограммах: $I_{N C} / I_{A M}$ и $\left(I_{N C}+I_{D 03}\right) / I_{A M}$ растут, $I_{D 03} / I_{N C}$ уменьшается.

Атомы $\mathrm{Si}$, как наиболее мелкие и не образующие соединений $\mathrm{c} \mathrm{Cu}, \mathrm{Nb}$ и $\mathrm{B}$, уже на ранних стадиях отжига практически все оказываются в нанокристаллах, возникающих, по-видимому, из зародышей с ОЦК ближним порядком. Атомы Fe имеют больший чем у $\mathrm{Si}$ размер и могут образовывать соединения, по крайней мере, с бором. Поэтому их подвижность ниже, чем у атомов кремния, но она увеличивается с ростом $T_{a n}$. При этом наверняка двух часов отжига достаточно, чтобы достичь максимального для этой температуры исхода атомов Fе из матрицы в нанокристаллы. Возможно, что одновременно с ростом $T_{a n}$ увеличивается и вероятность образования боридов железа, что все в большей степени препятствует его диффузии из матрицы в нанокристаллы.

Анализируя положения и ширины узких интенсивных пиков, которые представляют собой вклады от ОЦК-решетки нанокристаллов, можно оценить пара-

Таблица 2. Вклады отдельных фаз в рентгеновскую дифрактограмму: доли суммарных интенсивностей пиков, соответствующих нанокристаллам $\left(I_{N C}\right)$, аморфной матрице $\left(I_{A M}\right)$ и областям фазы $D 0_{3}\left(I_{D 03}=(111)_{D}+(200)_{D}+(311)_{D}+(222)_{D}\right)$, а также их отношения

\begin{tabular}{|c|c|c|c|c|c|c|}
\hline \multirow{2}{*}{$\begin{array}{c}\text { Температура } \\
\text { отжига, }{ }^{\circ} \mathrm{C}\end{array}$} & \multicolumn{3}{|c|}{$\begin{array}{c}\text { Доля в общей интенсивности } \\
\text { рассеяния, \% }\end{array}$} & \multicolumn{3}{|c|}{ Отношение интенсивностей } \\
\hline & $I_{N C}$ & $I_{A M}$ & $I_{D 03}$ & $I_{N C} / I_{A M}$ & $I_{D 03} / I_{N C}$ & $\left(I_{N C}+I_{D 03}\right) / I_{A M}$ \\
\hline 520 & $53.0(6)$ & $45.5(9)$ & $1.5(1)$ & $1.17(3)$ & $0.028(2)$ & $1.20(3)$ \\
\hline 540 & $55.5(5)$ & $42.9(9)$ & $1.6(1)$ & $1.29(3)$ & $0.029(2)$ & $1.33(3)$ \\
\hline 560 & $59.0(4)$ & $39.4(5)$ & $1.6(1)$ & $1.50(2)$ & $0.027(2)$ & $1.54(2)$ \\
\hline 580 & $60.8(4)$ & $37.6(5)$ & $1.6(1)$ & $1.62(2)$ & $0.026(2)$ & $1.66(3)$ \\
\hline 600 & $59.6(5)$ & $38.9(7)$ & $1.5(1)$ & $1.53(3)$ & $0.025(2)$ & $1.57(3)$ \\
\hline
\end{tabular}




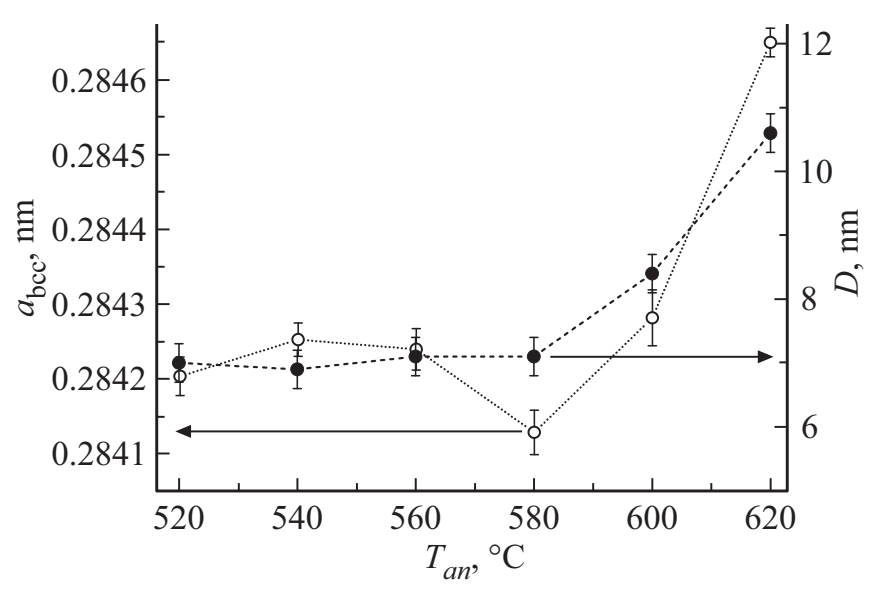

Рис. 6. Зависимость параметра решетки (светлые символы) и среднего размера (темные символы) ОЦК-нанокристаллов от температуры отжига $T_{a n}$.

метр решетки и размер областей когерентного рассеяния $[61,62]$, который соответствует среднему размеру нанокристаллов, образовавшихся в сплаве в результате отжига при температуре $T_{a n}$.

На рис. 6 приведены зависимости от $T_{a n}$ параметра решетки и среднего размера ОЦК-нанокристаллов в образцах сплава $\mathrm{Fe}_{73.5} \mathrm{Si}_{13.5} \mathrm{Nb}_{3} \mathrm{Cu}_{1} \mathrm{~B}_{9}$. Средний размер и параметр решетки нанокристаллов остаются практически неизменными при температурах отжига от 520 до $580^{\circ} \mathrm{C}$, начиная с $600^{\circ} \mathrm{C}$ наблюдается их рост, особенно резкий при $T_{a n}=620^{\circ} \mathrm{C}$. Стабильные значения параметров $a_{b c c}=0.284206 \mathrm{~nm}$ и $D \approx 7.0 \mathrm{~nm}$ соответствуют области оптимальных температур отжига для получения наилучших мягких магнитных свойств, их резкое увеличение - ухудшению свойств и началу вторичной кристаллизации аморфной матрицы.

Параметр решетки был определен с помощью метода наименьших квадратов по угловым положениям ОЦКпиков, полученных при МНК-разложении дифрактограмм (рис. 5). Оценка среднего размера нанокристаллов получена по формуле Шеррера [61] из ширины этих же пиков на полувысоте.

Прежде чем перейти к анализу результатов рентгенодифракционных исследований, следует уточнить, что имеется в виду под терминами „нанокристаллы“ и „аморфная матрица“. Обычно при МНК-разложении дифрактограмм подразумевается, что в разные наборы рефлексов дают вклад области материала, имеющие разные структуры. В случае нанокристаллического сплава ситуация несколько сложнее. Будем рассматривать нанокристалл как область сплава размером $D$, окруженную аморфной матрицей. Такой же средний размер нанокристаллов $\mathrm{FeSi}$ наблюдается для отожженного при $550^{\circ} \mathrm{C}$ образца, исследованного методом трансмиссионной электронной микроскопии [63,64]. Наблюдается разброс в оценках среднего размера нанокристаллов при отжиге сплава Finemet на воздухе при одина- ковой температуре, например, $525^{\circ} \mathrm{C}-$ от $\sim 7$ до $\sim 12 \mathrm{~nm}[9,10,23,43,65,66]$, но при этом в некоторых работах, например, в [43] в формуле Шеррера ошибочно используется не полная ширина, а полуширина пика, что завышало $D$ в два раза [62].

Термин „аморфная матрица“ более или менее уместен только для сплава в исходном состоянии, после закалки из расплава, до нанокристаллизующего отжига. Следует отметить, что в дифрактограмме сплава $\mathrm{Fe}_{73.5} \mathrm{Si}_{13.5} \mathrm{Nb}_{3} \mathrm{Cu}_{1} \mathrm{~B}_{9}$ в его исходном состоянии наблюдаются широкие диффузные пики [67]. Но расположение максимума первого пика при углах рассеяния $2 \theta \approx 20^{\circ}$, совпадающее с максимумом интенсивности в брэгговском рефлексе (110) для ОЦК-решетки железа, указывает на то, что в исходном состоянии имеются регионы с ОЦК ближним порядком в расположении атомов [58]. После нанокристаллизующего отжига, как следует из вышеприведенных вычислений, отношение $M e / \mathrm{B}=(22.9+3) / 9=2.88$, где $M e=$ Fе или Nb. Формально это означает, что бор может образовать с металлами соединения типа $M e_{2} \mathrm{~B}$ и $M e_{3} \mathrm{~B}$ со значительным преобладанием последних. Пики от этих соединений действительно наблюдаются как в наших дифрактограммах, так и в статьях других авторов, когда такие соединения в заметном количестве образуются после отжига при температуре выше $600^{\circ} \mathrm{C}$.

Для простоты положим, что в ОЦК-решетке нанокристалла нет вакансий и дефектов, но часть атомов железа в ней может быть замещена атомами кремния, которые, как известно [66], испытывают взаимное отталкивание и поэтому не могут быть ближайшими соседями. Атомов другого сорта нанокристалл не содержит. Количество замещающих атомов кремния и их распределение по узлам ОЦК-решетки изменяются только на начальных этапах отжига при заданной температуре, а к его концу эти изменения гарантированно заканчиваются. Распределение кремния по узлам решетки неоднородное: в части нанокристалла его содержание может приближаться к стехиометрическому - $\mathrm{Fe}_{3} \mathrm{Si}$, а в остальной части возникает неупорядоченный раствор $\alpha$-FeSi c низким содержанием кремния. В дифрактограмме вклад в ОЦКрефлексы будет давать весь нанокристалл, имеющий соответствующую ориентацию осей кристаллической решетки, а в $\mathrm{DO}_{3}$ - только та его часть, которая имеет упорядоченную структуру, близкую к стехиометрии $\mathrm{Fe}_{3} \mathrm{Si}$.

Предположим, что после нанокристаллизующего отжига при температуре $520^{\circ} \mathrm{C}$ в течение $2 \mathrm{~h}$ : (1) весь кремний переходит из аморфной матрицы в нанокристаллы, (2) в нанокристаллах около 80\% атомов железа находятся в упорядоченной фазе $D 0_{3}$. Первое предположение основывается на том, что содержащиеся в матрице $\mathrm{Nb}$ и В выталкивают кремний, атомы которого являются наиболее подвижными, и за два часа отжига он полностью перейдет из матрицы в нанокристаллы [3], а второе - на результатах, полученных методом ядерной гамма-резонансной (ЯГР) спектроскопии (эффект 
Мёссбауэра) [58]. При анализе распределения локальных окружений атомов железа по сверхтонким полям было показано, что в сплаве, содержащем $13.5 \%$ кремния, после отжига при температуре $T_{a n} 520^{\circ} \mathrm{C}$ в течение двух часов вокруг атомов железа преобладает координация, соответствующая локальному порядку типа $D 0_{3}$. Причем ее доля достигает примерно 0.8 от атомов железа в сильных сверхтонких полях нанокристалла, которым соответствуют большие магнитный момент и общая намагниченность. Остальная часть, около $1 / 5$ (20\%), находится в области нанокристалла, представляющей собой бедный кремнием неупорядоченный раствор $\alpha$-FeSi.

Поскольку весь кремний (13.5\%) находится в нанокристаллах, и большая его доля - в областях со структурой $D 0_{3}$, можно сделать грубую оценку количества атомов $\mathrm{Fe}$, образующих нанокристаллы. Предположим, что каждый нанокристалл примерно на $80 \%$ состоит из области со стехиометрическим составом $\mathrm{Fe}_{3} \mathrm{Si}$, а остальные $20 \%$ - это почти чистое железо. Тогда в областях $\mathrm{DO}_{3}$ окажется $13.5 \times 3=40.5 \%\left(\mathrm{Fe}_{3} \mathrm{Si}\right)$, а в областях $\alpha-\mathrm{FeSi}$, где концентрацию $\mathrm{Si}$ мы приняли близкой к нулю, $-40.5 / 0.8 \times 0.2=10.1 \%$ атомов железа. Следовательно, после отжига при температуре $520^{\circ} \mathrm{C}$ в течение $2 \mathrm{~h}$ в нанокристаллах будет находится примерно $40.5+10.1=50.6 \%$ атомов железа, в сумме $50.6+13.5=64.1 \%$ атомов железа и кремния. Средняя концентрация кремния в нанокристаллах составит $13.5 / 64.1 \approx 21 \%$. В матрице останется $73.5-50.6=22.9 \%$ атомов железа, 3\% ниобия, 9\% бора и $1 \%$ меди, всего около $35.9 \%$ атомов сплава.

Также из исследований методом ЯГР-спектроскопии [58] известно, что после двухчасового отжига сплава $\mathrm{Fe}_{76} \mathrm{Si}_{11} \mathrm{Nb}_{3} \mathrm{Cu}_{1} \mathrm{~B}_{9}$ при $520^{\circ} \mathrm{C}$ доля атомов $\mathrm{Fe}$ в областях $D 0_{3}$ нанокристаллов составляет $\sim 0.72$. Из расчетов, аналогичных сделанным выше для $\mathrm{Fe}_{73.5} \mathrm{Si}_{13.5} \mathrm{Nb}_{3} \mathrm{Cu}_{1} \mathrm{~B}_{9}$, получаем количественные оценки: в нанокристаллах находится $\sim 45.8 \%$ атомов железа из $76 \%$ в сплаве, вместе с кремнием $\sim 56.8 \%$ атомов сплава, а средняя концентрация кремния в них $\sim 19 \%$. В матрице остается $43.2 \%$ атомов сплава, из которых $30.2 \%$ - железо, $9 \%-$ бор, $3 \%-\mathrm{Nb}$ и $1 \%-\mathrm{Cu}$. Из соотношения $M e / \mathrm{B}=(30.2+3) / 9=3.7$, можно ожидать, что если бор вступает в соединение с металлами, то преимущественно в $\mathrm{Me}_{3} \mathrm{~B}$, а избыточное, не связанное с бором железо, по всей видимости, и будет диффундировать из матрицы в нанокристаллы при повышении $T_{a n}$.

Теперь можно оценить влияние увеличения содержания железа в нанокристаллах на изменение магнитных свойств. Коэрцитивная сила $H_{c}$ и начальная магнитная проницаемость $\mu_{i}$ нанокристаллических сплавов в рамках модели случайной анизотропии $[3,47]$, в которой рассматривается набор связанных обменным взаимодействием зерен размером $D$ со случайной ориентацией осей легкого намагничивания, в том случае, если нет никаких других видов магнитной анизотропии, кроме маг- нитокристаллической $K_{1}$, описываются соотношениями:

$$
\begin{gathered}
H_{c}=p_{c} \frac{\langle K\rangle}{J_{s}} ; \\
\mu_{1}=p_{\mu} \frac{J_{s}^{2}}{\mu_{0}\langle K\rangle},
\end{gathered}
$$

где усредненная плотность энергии магнитной анизотропии определяется по формуле

$$
\langle K\rangle \approx v_{\mathrm{cr}}^{2} K_{1}\left(D / L_{0}\right)^{6}=v_{\mathrm{cr}}^{2} D^{6} K_{1}^{4} / A^{3} .
$$

Здесь $J_{s}-$ среднее намагничивание насыщения материала, $v_{\mathrm{cr}}-$ объемная доля зерен, $p_{c}$ и $p_{\mu}-$ безразмерные факторы близкие к единице, $\mu_{0}$ - магнитная постоянная, $L_{0}$ - длина и $A-$ константа жесткости ферромагнитного обмена в кристаллическом $\alpha$-FeSi сплаве, содержащем $20 \%$ кремния.

После отжига при температуре $520^{\circ} \mathrm{C}$ в течение $2 \mathrm{~h}$ средняя концентрация кремния в нанокристаллах сплава $\mathrm{Fe}_{73.5} \mathrm{Si}_{13.5} \mathrm{Nb}_{3} \mathrm{Cu}_{1} \mathrm{~B}_{9}$ составляет $21 \%$, а в нанокристаллах сплава с более низким содержанием кремния $\mathrm{Fe}_{76} \mathrm{Si}_{11} \mathrm{Nb}_{3} \mathrm{Cu}_{1} \mathrm{~B}_{9}-19 \%$. Известно, что константа магнитокристаллической анизотропии, $K_{1}$ в железокремнистых сплавах зависит от концентрации кремния.

Например, на рис. 7, заимствованном из базы данных [68], приведена концентрационная зависимость $K_{1}$, определенная путем измерения минимального крутящего момента монокристаллических дисков, необходимого для их вращения в постоянном магнитном поле, при комнатной температуре. При увеличении концентрации кремния константа $K_{1}$ постепенно уменьшается, что ведет к улучшению магнитомягких свойств $\alpha$-железа по мере добавления кремния.

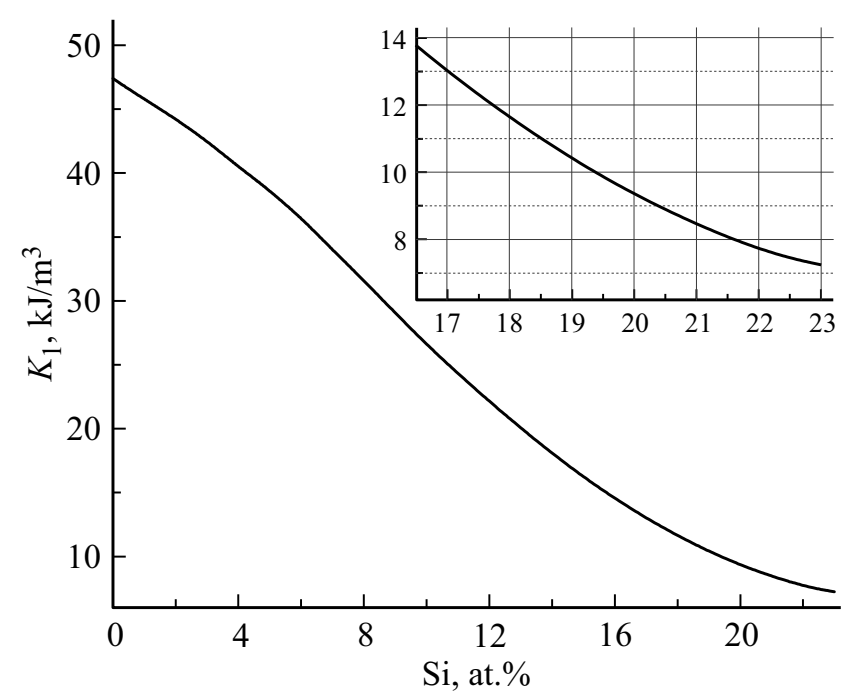

Рис. 7. Концентрационная зависимость магнитокристаллической анизотропии (МСА) в сплавах железо-кремний [68]. На вставке приведена наиболее важная для анализа результатов настоящих исследований область концентраций от 17 до 23 at.\% Si с линиями сетки для удобства рассмотрения значений концентраций и соответствующих значений константы $K_{1}$. 
Таблица 3. Вклады отдельных фаз в рентгеновскую дифрактограмму $I_{N C}, I_{A M}, I_{D 03}$ и $I_{N C}+I_{D 03}$, средняя концентрация кремния в нанокристаллах $C_{\mathrm{Si}}$, соответствующие значения констант магнитокристаллической анизотропии $K_{1}$ и рассчитанные с их использованием относительные значения коэрцитивной силы $R_{1}$ (без учета среднего размера нанокристаллов $\left.D\right)$ и $R_{2}($ с учетом $D)$, отнесенные к значению коэрцитивной силы при $T_{a n}=520^{\circ} \mathrm{C}: R_{1,2}=H_{c}\left(T_{a n}\right) / H_{c}\left(520^{\circ} \mathrm{C}\right)$

\begin{tabular}{c|c|c|c|c|c|c|c|c}
\hline$T_{a n},{ }^{\circ} \mathrm{C}$ & $I_{N C}, \%$ & $I_{A M}, \%$ & $I_{D 03}, \%$ & $I_{N C}+I_{D 03}, \%$ & $C_{\mathrm{Si}}, \%$ & $K_{1}, \mathrm{~kJ} / \mathrm{m}^{3}$ & $R_{1}$ & $R_{2}$ \\
\hline 520 & $53.0(6)$ & $45.5(9)$ & $1.5(1)$ & 54.5 & 21.0 & 8.4 & 1.0 & 1.0 \\
540 & $55.5(5)$ & $42.9(9)$ & $1.6(1)$ & 57.1 & 20.0 & 9.4 & 1.6 \\
560 & $59.0(4)$ & $39.4(5)$ & $1.6(1)$ & 61.6 & 18.6 & 10.9 & 2.8 \\
580 & $60.8(4)$ & $37.6(5)$ & $1.6(1)$ & 62.4 & 18.3 & 11.2 & 3.1 \\
600 & $59.6(5)$ & $38.9(7)$ & $1.5(1)$ & 61.1 & 18.7 & 10.8 & 2.7 & 8.1
\end{tabular}

Значения константы $K_{1}$ можно приближенно определить из графика, приведенного на вставке в правой верхней части рис. 7. В случае сплава $\mathrm{Fe}_{73.5} \mathrm{Si}_{13.5} \mathrm{Nb}_{3} \mathrm{Cu}_{1} \mathrm{~B}_{9}$ константа $K_{1(1)} \approx 8.5 \mathrm{~kJ} / \mathrm{m}^{3}$, для сплава $\mathrm{Fe}_{76} \mathrm{Si}_{11} \mathrm{Nb}_{3} \mathrm{Cu}_{1} \mathrm{~B}_{9} K_{1(2)} \approx 10.4 \mathrm{~kJ} / \mathrm{m}^{3}$.

Предполагая, что размер и доля нанокристаллов не изменяются, вычислим, используя формулы (1) и (3), отношение

$$
\frac{H_{\mathrm{c}(1)}}{H_{\mathrm{c}(2)}} \approx \frac{K_{1(1)}^{4}}{K_{1(2)}^{4}}=\frac{8.5^{4}}{10.4^{4}} \approx 0.45 .
$$

Получается, что только из-за уменьшения концентрации кремния в сплаве с 13.5 до 11 at.\% и уменьшения концентрации кремния в нанокристаллах от 0.21 до 0.19 и, как следствие, из-за увеличения магнитокристаллической анизотропии в нанокристаллах коэрцитивная сила (1) увеличивается в 2.2 раза. В то же время начальная магнитная проницаемость (2) понижается в 2.2 раза.

Для объяснения влияния температуры двухчасового отжига на мягкие магнитные свойства предположим, что по сравнению с химическим составом нанокристаллов и матрицы в сплаве $\mathrm{Fe}_{73.5} \mathrm{Si}_{13.5} \mathrm{Nb}_{3} \mathrm{Cu}_{1} \mathrm{~B}_{9}$, полученном в результате отжига при температуре $T_{a n}=520^{\circ} \mathrm{C}$, при более высоких значениях $T_{a n}$ из аморфной фазы в кристаллическую дополнительно перемещаются только атомы железа. Тогда в дифрактограмме весь прирост объемной доли нанокристаллической фазы от 53 до 61\% целиком объясняется дополнительной диффузией атомов железа из матрицы в нанокристаллы. В рамках этого предположения легко оценить концентрацию кремния в нанокристаллах при разных температурах отжига. Она уменьшается на три процента, с 21 почти до $18 \%$. Из графика концентрационной зависимости плотности энергии магнитокристаллической анизотропии (рис. 7) можно определить значения $K_{1}$ при разных концентрациях $C_{\mathrm{Si}}$ в нанокристаллах и рассчитать, используя формулы (1) и (3), коэффициенты $R_{1}=H_{c}\left(T_{a n}\right) / H_{c}\left(520^{\circ} \mathrm{C}\right)$, которые описывают относительные изменения коэрцитивной силы для каждого значения $T_{a n}$. Они приведены в предпоследнем столбце табл. 3.

Аналогичный расчет коэффициентов $R_{2}=$ $=H_{c}\left(T_{a n}\right) / H_{c}\left(520^{\circ} \mathrm{C}\right)$ выполнен с учетом изменяющего-

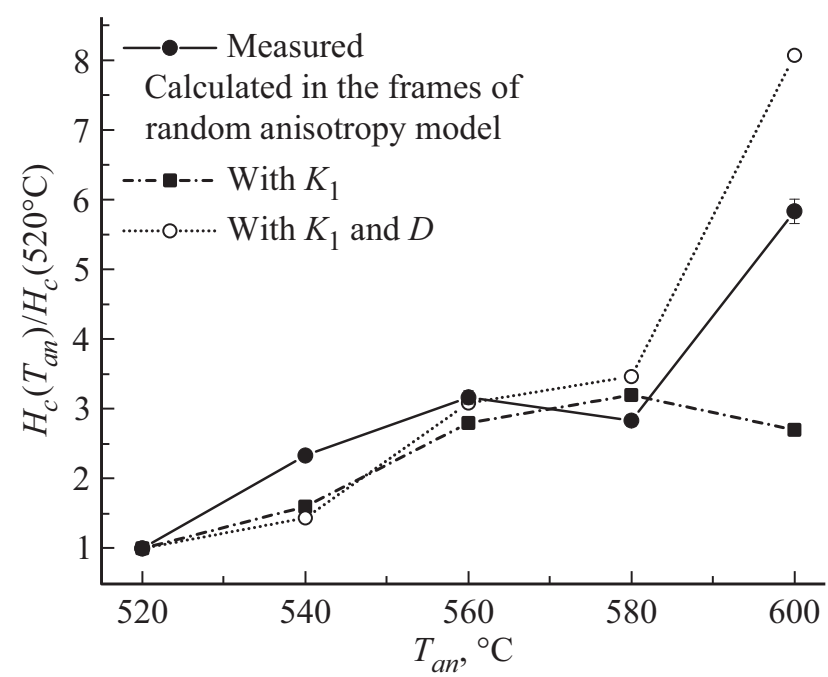

Рис. 8. Зависимости относительной величины коэрцитивной силы $H_{c}\left(T_{a n}\right) / H_{c}\left(520^{\circ} \mathrm{C}\right)$ от температуры отжига образцов сплава $\mathrm{Fe}_{73.5} \mathrm{Si}_{13.5} \mathrm{Nb}_{3} \mathrm{Cu}_{1} \mathrm{~B}_{9}$, полученные в результате экспериментальных измерений петель магнитного гистерезиса, см. табл. 1 (темные кружки), а также рассчитанные с учетом изменения только константы магнитокристаллической анизотропии $K_{1}$ (квадраты) и с учетом изменения среднего размера нанокристаллов $D$ (светлые кружки).

ся среднего размера нанокристаллов $D$. Использованы значения $D$ в зависимости от $T_{a n}$, показанные на рис. 6 , результаты расчетов также приведены в табл. 3. На рис. 8 приведены графики, демонстрирующие тенденции изменения величины коэрцитивной силы, измеренной и рассчитанной (как с учетом изменения только константы $K_{1}$, так и с учетом изменения и константы $K_{1}$, и среднего размера $D$ ) для образцов сплава $\mathrm{Fe}_{73.5} \mathrm{Si}_{13.5} \mathrm{Nb}_{3} \mathrm{Cu}_{1} \mathrm{~B}_{9}$, после отжига при температуре $T_{a n}$.

Графики зависимости относительных значений коэрцитивной силы от температуры нанокристаллизующего отжига, приведенные на рис. 8, показывают, что модельный расчет в рамках модели случайной магнитной анизотропии, основанный на результатах фазового анализа рентгеновских дифрактограмм, довольно хорошо описывает тенденцию увеличения коэрцитивной силы по мере увеличения температуры отжига до значения 
$T_{a n}=580^{\circ} \mathrm{C}$. После этой точки результат измерений петли магнитного гистерезиса идет (продолжает идти) вверх в то время, как результат расчета по формулам (1) и (3) с учетом только магнитокристаллической анизотропии поворачивает вниз.

Если, в соответствии с формулой (3), учесть изменение среднего размера нанокристаллов $D$ в зависимости от температуры отжига (рис. 6), то получается зависимость, обозначенная на рис. 8 светлыми кружками. Можно сделать заключение, что модель случайной магнитной анизотропии с учетом изменения величины магнитокристаллической анизотропии и средних размеров нанокристаллов достаточно хорошо описывает изменение магнитных свойств нанокристаллических сплавов типа Finemet $(\mathrm{FeSiNbCuB})$ в зависимости от температуры отжига, при которой в этих сплавах происходит образование нанокристаллов.

\section{4. Заключение}

Исследовалась зависимость мягких магнитных свойств и атомной структуры сплава $\mathrm{Fe}_{73.5} \mathrm{Si}_{13.5} \mathrm{Nb}_{3} \mathrm{Cu}_{1} \mathrm{~B}_{9}$ от температуры нанокристаллизующего отжига продолжительностью два часа в интервале температур от 520 до $620^{\circ} \mathrm{C}$ с шагом в $20^{\circ} \mathrm{C}$. Показано, что по мере увеличения температуры петли магнитного гистерезиса становятся все более широкими и наклонными, магнитомягкие свойства сплава ухудшаются, что находится в соответствии с результатами магнитных измерений, полученными ранее $[3,8]$. Изменения в ходе температурной зависимости намагниченности насыщения двух образцов сплава, предварительно отожженных при двух температурах 520 и $540^{\circ} \mathrm{C}$, в частности, перемещение точки Кюри аморфной матрицы в направлении меньших температур, показывают, что, скорее всего, в ней уменьшается содержание железа из-за его дополнительной диффузии из матрицы в нанокристаллы при более высокой температуре отжига. Ранее было показано [35,58], что повышение концентрации железа в нанокристаллах приводит к увеличению параметра ОЦК-решетки нанокристаллов и уменьшению в них объемной доли фазы $D 0_{3}$ вплоть до ее полного исчезновения. В то же время, несмотря на рост индукции насыщения, мягкие магнитные свойства ухудшаются - повышается коэрцитивная сила, увеличивается наклон петли магнитного гистерезиса.

Количественный фазовый анализ рентгеновских дифрактограмм с их разложением на отдельные вклады от нанокристаллов и аморфной матрицы показывает, что по мере роста температуры отжига вклад нанокристаллов увеличивается, а вклад матрицы настолько же уменьшается. Отношение объемных долей нанокристаллов и матрицы между температурами отжига 520 и $580^{\circ} \mathrm{C}$ увеличивается на $32 \%$. Средний размер и параметр решетки нанокристаллов остаются практически неизменными при температурах отжига от 520 до $580^{\circ} \mathrm{C}$.
Начиная с температуры $600^{\circ} \mathrm{C}$ наблюдается их рост, особенно резкий при температуре $620^{\circ} \mathrm{C}$. Стабильные значения параметра ОЦК-решетки и среднего размера нанокристаллов соответствуют области оптимальных температур отжига для получения наилучших мягких магнитных свойств, их резкое увеличение - ухудшению свойств и началу вторичной кристаллизации аморфной матрицы.

Если сравнить структуру и свойства нанокристаллических сплавов $\mathrm{Fe}_{73.5} \mathrm{Si}_{13.5} \mathrm{Nb}_{3} \mathrm{Cu}_{1} \mathrm{~B}_{9}$ и $\mathrm{Fe}_{76} \mathrm{Si}_{11} \mathrm{Nb}_{3} \mathrm{Cu}_{1} \mathrm{~B}_{9}$ с разным содержанием железа и кремния [58], то оказывается, что в результате уменьшения среднего содержания кремния в образцах, предварительно подвергнутых отжигу при температуре $520^{\circ} \mathrm{C}$ в течение $2 \mathrm{~h}$, уменьшается объемная доля нанокристаллов, упорядоченная в фазе $\mathrm{DO}_{3}$, с 80 до 72\%. Это происходит из-за того, что средняя концентрация атомов кремния в нанокристаллах уменьшается с 21 до 19\%, удаляясь от стехиометрического для $\mathrm{Fe}_{3} \mathrm{Si}$ значения 25\%. Известно, что в массивных железокремнистых сплавах при увеличении концентрации кремния уменышается константа магнитокристаллической анизотропии - $K_{1}$. Если в рамках теоретической модели случайной магнитной анизотропии [3] для оценки изменений магнитных свойств использовать соответствующие значения константы $K_{1}$, то оказывается, что только из-за уменьшения концентрации кремния в сплаве коэрцитивная сила увеличивается в 2.2 раза, а начальная магнитная проницаемость понижается в 2.2 раза.

В рамках предположения о том, что весь прирост объемной доли нанокристаллической фазы по мере роста температуры отжига целиком объясняется дополнительной диффузией атомов железа из матрицы в нанокристаллы, оценивается концентрация кремния в нанокристаллах при разных температурах отжига. Она уменьшается с 21 до $18 \%$, константа $K_{1}$ увеличивается от 8.4 до $11.2 \mathrm{~kJ} / \mathrm{m}^{3}$, а коэрцитивная сила увеличивается в три раза. Имеющееся расхождение в поведении относительных значений коэрцитивной силы при температурах отжига между 580 и $600^{\circ} \mathrm{C}$, измеренных экспериментально и рассчитанных в рамках модели случайной анизотропии, исправляется с помощью учета изменения среднего размера нанокристаллов. Таким образом, модель случайной магнитной анизотропии с учетом как магнитокристаллической анизотропии, так и влияния средних размеров нанокристаллов достаточно хорошо описывает изменение магнитных свойств нанокристаллических сплавов типа Finemet $(\mathrm{FeSiNbCuB})$ в зависимости от температуры отжига, при которой в этих сплавах происходит образование нанокристаллов.

Следовательно, уширение петли магнитного гистерезиса по мере увеличения температуры продолжительного нанокристаллизующего отжига объясняется разной подвижностью атомов железа и кремния при их диффузионном движении из аморфной матрицы в нанокристаллы. При любой фиксированной температуре отжига атомы кремния быстрее переходят из матрицы в 
нанокристаллы, чем атомы железа. При более высокой температуре в результате продолжительной выдержки все большая доля атомов железа переходит из матрицы в нанокристаллы, что существенно увеличивает их магнитную жесткость.

\section{Финансирование работы}

Работа выполнена в рамках государственного задания по теме „Магнит“ № AАAА-А18-118020290129-5, а также проекта № 18-10-2-5 Программы УрО РАН.

\section{Конфликт интересов}

Авторы заявляют, что у них нет конфликта интересов.

\section{Список литературы}

[1] U. Enz. Magnetism and Magnetic Materials: Historical Developments and Present Role in Industry and Technology. In: Handbook of Magnetic Materials / Ed. E.P. Wohlfarth. North-Holland Publishing Company, Amsterdam (1982). V. 3. P. 1. https://doi.org/10.1016/S1574-9304(05)80087-2

[2] Y. Yoshizawa, S. Oguma, K. Yamauchi. J. Appl. Phys. 64, 6044 (1988). https://doi.org/10.1063/1.342149

[3] G. Herzer. Nanocrystalline soft magnetic Alloys. In: Handbook of Magnetic Materials / Ed. K.H.J. Buschow. Vacuumschmelze, Hanau (1997). V. 10. P. 415. https://doi.org/10.1016/S1567-2719(97)10007-5

[4] F. Fiorillo, G. Bertotti, C. Appino, M. Pasquale. Soft Magnetic Materials. In: Wiley Encyclopedia of Electrical and Electronics Engineering. John Wiley \& Sons, Inc., Hoboken (2016). P. 1. doi:10.1002/047134608x.w4504.pub2

[5] M. Müller, H. Harada, H. Warlimont. Magnetic Materials. In: Springer Handbook of Materials Data (2nd ed.). / Eds H. Warlimont, W. Martienssen. Springer International Publishing, N.Y. (2018). P. 753.

DOI https://doi.org/10.1007/978-3-319-69743-7

[6] F. Johnson, A. Hsaio, C. Ashe, D. Laughlin, D. Lambeth, Mi.E. McHenry. Proceedings of the 1st IEEE Conference on Nanotechnology (IEEE-NANO 2001). (28-30 october 2001) Maui, Hawaii. Institute of Electrical and Electronics Engineers, Inc, 1-6 (2001). ISBN: 0-7803-7215-8

[7] M.A. Willard, M. Daniil. Nanocrystalline Soft Magnetic Alloys. Two Decades of Progress. In: Handbook of Magnetic Materials / Ed. K.H.J. Buschow. Elsevier, Amsterdam (2013). Ch. 4. V. 21. P. 173. DOI: 10.1016/B978-0-444-59593-5.00004-0

[8] G. Herzer. IEEE Trans. Magn. 26, 1397 (1990). DOI: $10.1109 / 20.104389$

[9] R.S. Turtelli, V.H. Duong, R. Grössinger, M. Schwetz, E. Ferrara, N. Pillmayr. IEEE Trans. Magn. 36, 508 (2000). DOI: $10.1109 / 20.825825$

[10] M. LoBue, V. Basso, C. Beatrice, P. Tiberto. IEEE Trans. Magn. 36, 5, 3035 (2000). DOI: 10.1109/20.908669

[11] S.V. Komogortsev, G.S. Krainova, N.V. Il'in, V.S. Plotnikov, L.A. Chekanova, I.V. Nemtsev, G.Yu. Yurkin, R.S. Iskhakov, D.A. Yatmanov. Inorg. Mater. Appl. Res. 11, 177 (2020). https://doi.org/10.1134/S2075113320010219
[12] F. Wan, A. He, J. Zhang, J. Song, A. Wang, C. Chang, X. Wang. J. Electron. Mater. 45, 4913 (2016). https://doi.org/10.1007/s11664-016-4643-X

[13] T. Günes. J. Non-Cryst. Solids 513, 97 (2019). Doi.org/10.1016/j.jnoncrysol.2019.03.024

[14] M. Xiao, Z. Zheng, L. Ji, X. Liu, Z. Qiu, D. Zeng. J. NonCryst. Solids 521, 119546 (2019).

[15] H.A. Shivaee, A. Castellero, P. Rizzi, P. Tiberto, H.R.M. Hosseini, M. Baricco. Met. Mater. Int. 19, 643 (2013). doi: $10.1007 / \mathrm{s} 12540-013-4003-9$

[16] C. Smith, S. Katakam, S. Nag, Y.R. Zhang, J.Y. Law, R.V. Ramanujan, N.B. Dahotre, R. Banerjee. Met. Mater. Trans. A 45, 2998 (2014).

[17] S. Atalay, P.T. Squire, I. Todd, H.A. Davies, M.R.J. Gibbs. Magnetoelastic properties of Al-substituted Finemet alloys. IEEE International Magnetics Conference (INTERMAG2000). (9-13 april 2000), Toronto, Ontario, Canada. BD-03 (2000). DOI: 10.1109/INTMAG.2000.871900

[18] G. Manginas, G. Ababei, A. Damian, G. Stoian, M. Grigoras, M. Tibu, H. Chiriac, T.A. Ovari, N. Lupu. Collective behavior of nanograins in Co-substituted Fe-based nanocrystalline alloys. IEEE International Magnetics Conference (INTERMAG-2018), (23-27 april 2018), Singapore. 1800BB12 (2018). DOI: 10.1109/INTMAG.2018.8508102

[19] V.H. Duong, R.S. Turtelli, R. Grossinger. IEEE Trans. Magn. 32, 4821 (1996). DOI: 10.1109/20.539163

[20] Q. Zhu, Z. Chen, S. Zhang, Q. Li, Y. Jiang, P. Wu, K. Zhang. J. Magn. Magn. Mater. 487, 165297 (2019).

[21] Y. Han, R. Wei, Z. Li, F. Li, A. Wang. J. Mater. Sci.: Mater. Electron. 28, 10555 (2017). DOI: 10.1007/s10854-017-6829-2

[22] I. Todd, H.A. Davies, M.R.J. Gibbs, D. Kendall, R.V. Major. Mater. Res. Soc. Symp. (Symposium H - Advanced Hard and Soft Magnetic Materials) 577, 493 (1999). DOI: https://doi.org/10.1557/PROC-577-493

[23] H.S. Todd Liu, C.H. Yin, X.X. Miao, Z.D. Han, D.H. Wang, Y.W. Du. Mater. Sci. Technol. 24, 45 (2008).

[24] P. Li, Z.X. Zheng, H.L. Su, Y.C. Wu. Mater. Sci. Technol. 29, 1324 (2013). https://doi.org/10.1179/1743284713Y.0000000276

[25] H.Q. Guo, H. Kronmüller, T. Dragon, Z.H. Cheng, B.G. Shen. Phys. Rev. B 62, 9, 5760 (2000). DOI: https://doi.org/10.1103/PhysRevB.62.5760

[26] S. Kwon, S. Kim, H. Yim. Curr. Appl. Phys. 20, 37 (2020). https://doi.org/10.1016/j.cap.2019.10.003

[27] L. Ling, Y. Biao, G. Le-ding, Y. Sha, C. Zhi-hui. Effect of annealing heat treatments on soft magnetic properties of Finemet alloy. IEEE International Nanoelectronics Conference (2nd INEC 2008). 458 (2008).

[28] O. Geoffroy, N. Boust, H. Chazal, S. Flury, J. Roudet. AIP Adv. 8, 047712 (2018). https://doi.org/10.1063/1.4993706

[29] R. Shi, Z. Wang, Y. Han. AIP Adv. 9, 055222 (2019). https://doi.org/10.1063/1.5090554

[30] Y. Yoshizawa, K. Yamauchi. IEEE Translat. J. Magn. Jpn. 5, 1070 (1990). DOI: 10.1109/TJMJ.1990.4564397

[31] S. Kwon, S. Kim, H. Yim, K.H. Kang, C.S. Yoon. J. Alloys Compd. 826, 154136 (2020). https://doi.org/10.1016/j.jallcom.2020.154136

[32] X.Y. Zhang, F.X. Zhang, J.W. Zhang, W. Yu, M. Zhang, J.H. Zhao, R.P. Liu, Y.F. Xu, W.K. Wang. J. Appl. Phys. 84, 1918 (1998). https://doi.org/10.1063/1.368319

[33] А.А. Глазер, Н.М. Клейнерман, В.А. Лукшина, А.П. Потапов, В.В. Сериков. ФММ 12, 56 (1991). 
[34] G. Herzer. IEEE Trans. Magn. 30, 6, 4800 (1994). DOI: https://doi.org/10.1557/jmr.2016.324

[35] В.В. Сериков, Н.М. Клейнерман, Е.Г. Волкова, В.А. Лукшина, А.П. Потапов, А.В. Свалов. ФММ 102, 3, 290 (2006).

[36] G. Herzer, V. Budinsky, C. Polak. Phys. Status Solidi B 248, 10, 2382 (2011). DOI 10.1002/pssb.201147088

[37] X. Fan, X. He, R. Nutor, R. Pan., J. Zheng, H. Ye, F. Wu, J. Jiang, Y. Fang. J. Magn. Magn. Mater. 469, 349 (2019). https://doi.org/10.1016/j.jmmm.2018.08.078

[38] Z. Xue, X. Li, S. Sohrabi, Y. Ren, W. Wang. Metals 10, 122 (2020). https://doi.org/10.3390/met10010122

[39] Y.X. Wang, G.N. Zhao, B. Yan, H.Y. Wang, W. Lu, Y. Zhang. IEEE Trans. Appl. Supercond. 20, 1638 (2010). DOI: 10.1109/TASC.2010.2044236

[40] L.K. Varga, E. Kid-Koszb, E. Zsoldos, E. Bakos. IEEE Trans. Magn. 30, 552 (1994). DOI: 10.1109/20.312333

[41] L.K. Varga, V. Franco, A. Kákay, Gy. Kovács, F. Mazaleyrat. IEEE Trans. Magn. 37, 2229 (2001). DOI: 10.1109/20.951132

[42] P. Allia, M. Baricco, P. Tiberto, F. Vinai. J. Appl. Phys. 74, 3137 (1993). https://doi.org/10.1063/1.354581

[43] P. Li, H.L. Su, Y.J. Song, Y.C. Wu. Mater. Sci. Technol. 29, 460 (2013). https://doi.org/10.1179/1743284712Y.0000000160

[44] J. Kováč, B. Kunca, L. Novák. J. Magn. Magn. Mater. 502, 166555 (2020). https://doi.org/10.1016/j.jmmm.2020.166555

[45] G. Herzer. Soft Magnetic Materials - Nanocrystalline Alloys. Handbook of Magnetism and Advanced Magnetic Materials. John Wiley \& Sons, Ltd., Hoboken (2007). doi: $10.1002 / 9780470022184 . \mathrm{hmm} 402$

[46] G. Herzer. IEEE Trans. Magn. 25, 3327 (1989). DOI: $10.1109 / 20.42292$

[47] R. Alben, J. Becker, M.C. Chi. J. Appl. Phys. 49, 1653 (1978). https://doi.org/10.1063/1.324881

[48] W.M. Yang, H.S. Liu, C.C. Dun, Y.C. Zhao, L.M. Dou. Mater. Sci. Technol. 28, 12, 1465 (2012). https://doi.org/10.1179/1743284712Y.0000000074

[49] L. Varga, F. Mazaleyrat. Magnetic Decoupling in Soft Magnetic Nanocrystalline Alloys. In: Properties and Applications of Nanocrystalline Alloys from Amorphous Precursors. NATO Science Series (Ser. II. Mathem., Phys. Chem.). / Eds B. Idzikowski, P. Švec, M. Miglierini. Springer, Dordrecht (2005). V. 184. P. 157. https://doi.org/10.1007/1-4020-2965-9_14

[50] O. Kubaschewski. Phase Diagrams of Binary Fe-based Systems. Springer-Verlag, Berlin, Heidelberg (1982). 185 p. ISBN 978-3-662-08024-5(eBook)

[51] K. Hono, D.H. Ping, M. Ohnuma, H. Onodera. Acta Mater. 47, 3, 997 (1999). https://doi.org/10.1016/S13596454(98)00392-9

[52] Y. Wang, Y. Zhang, A. Takeuchi, A. Makino, Y. Kawazoe. J. Appl. Phys. 120, 145102 (2016). https://doi.org/10.1063/1.4964433

[53] K. Hono, T. Sakurai. Appl. Surf. Sci. 87-88, 166 (1995). https://doi.org/10.1016/0169-4332(94)00513-3

[54] R. Jha, D.R. Diercks, N. Chakraborti, A.P. Stebner, C.V. Ciobanu. Scr. Mater. 162, 331 (2019). https://doi.org/10.1016/j.scriptamat.2018.11.039

[55] Z. Yu, Y. Ying, W.Y. Xin, L. Wei, Y. Biao. Sci. China Phys. Mech. Astron. 56, 1887 (2013). doi: $10.1007 / \mathrm{s} 11433-013-5133-2$

[56] M. Matsuura, M. Nishijima, K. Takenaka, A. Takeuchi, H. Ofuchi, A. Makino. J. Appl. Phys. 117, 17A324-1 (2015).
[57] K. Hono. Prog. Mater. Sci. 47, 621 (2002). https://doi.org/10.1016/S0079-6425(01)00007-X

[58] N.V. Ershov, Yu.P. Chernenkov, V.I. Fedorov, V.A. Lukshina, N.M. Kleinerman, V.V. Serikov, A.P. Potapov, N.K. Yurchenko. In: Nanocrystal. In: Tech, Rijeka (2011). P. 415. ISBN 978-953-307-199-2

[59] O. Zivotský, Y. Jirásková, A. Hendrych, V. Matejka, L. Klimsa, and J. Bursík. IEEE Trans. Magn. 48, 4, 1367 (2012). DOI: 10.1109/TMAG.2011.2171479

[60] J.A. Moya, S.G. Caramella, C. Berejnoib. J. Magn. Magn. Mater. 476, 248 (2019). https://doi.org/10.1016/j.jmmm.2019.01.008

[61] B.E. Warren. X-ray diffraction. Addison-Wesley, N.Y. (1969). $563 \mathrm{p}$.

[62] B.D. Cullity, S.R. Stock. Elements of X-Ray Diffraction. 3rd ed. Prentice-Hall Inc., New Jersey (2001). 531 p.

[63] В.А. Милютин, И.В. Гервасева, Е. Beaugnon, В.С. Гавико, Е.Г. Волкова. ФММ 118, 493 (2017).

[64] В.С. Цепелев, Ю.Н. Стародубцев, В.Я. Белозеров. ФММ 119, 882 (2018).

[65] F. Mazaleyrat, L.K. Varga. IEEE Trans. Magn. 37, 4, 2232 (2001). DOI: $10.1109 / 20.951133$

[66] О.И. Горбатов, А.Р. Кузнецов, Ю.Н. Горностырев, А.В. Рубан, Н.В. Ершов, В.А. Лукшина, Ю.П. Черненков, В.И. Федоров. ЖЭТФ 139, 5, 969 (2011). DOI: $10.1134 / \mathrm{S} 1063776111040066$

[67] Ю.П. Черненков, Н.В. Ершов, В.И. Федоров, В.А. Лукшина, А.П. Потапов. ФТТ 52, 3, 514 (2010). DOI: $10.1134 / \mathrm{S} 1063783410030169$

[68] G. Bertotti, F. Fiorillo. In: Magnetic Alloys for Technical Applications. Soft Magnetic Alloys, Invar and Elinvar Alloys / Ed. H.P.J. Wijn. Springer-Verlag, Berlin (1994). P. 51. $\mathrm{https}: / /$ materials.springer.com/lb/docs/sm_lbs_978-3-54047246-9_16

Редактор Е.Ю. Флегонтова 